\title{
Roles of energy conservation and climate feedback in Bjerknes compensation: a coupled modeling study
}

\author{
Haijin Dai ${ }^{1,2} \cdot$ Haijun Yang ${ }^{1} \cdot$ Jie Yin $^{1}$
}

Received: 25 April 2016 / Accepted: 5 October 2016 / Published online: 17 October 2016

(C) The Author(s) 2016. This article is published with open access at Springerlink.com

\begin{abstract}
The roles of energy balance and climate feedback in Bjerknes compensation (BJC) are studied through wind-perturbation experiments in a coupled climate model. Shutting down surface winds over the ocean causes significant reductions in both wind-driven and thermohaline overturning circulations, leading to a remarkable decrease in poleward ocean heat transport (OHT). The sea surface temperature (SST) responds with an increasing meridional gradient, resulting in a stronger Hadley Cell, and thus an enhanced atmosphere heat transport (AHT), compensating the OHT decrease. This is the so-called BJC. Coupled model experiments confirm that the occurrence of BJC is an intrinsic requirement of local energy conservation, and local climate feedback determines the degree of BJC, consistent with our previous theoretical results. Negative (positive or zero) local feedback results in AHT change undercompensating (overcompensating or perfectly compensating) OHT change. Using the radiative kernel technique, the general local feedback between the radiative balance at the top of the atmosphere and surface temperature can be partitioned into individual feedbacks that are related to perturbations in temperature, water vapor, surface albedo, and clouds. We find that the overcompensation in the tropics (extratropics) is mainly caused by positive feedbacks related to water vapor and clouds (surface albedo). The longwave feedbacks related to SST and atmospheric
\end{abstract}

Haijun Yang

hjyang@pku.edu.cn

1 Laboratory for Climate and Ocean-Atmosphere Studies (LaCOAS), Department of Atmospheric and Oceanic Sciences, School of Physics, Peking University, 209 Chengfu Road, Beijing 100871, China

2 Academy of Ocean Science and Engineering, National University of Defense Technology, Changsha, Hunan, China temperature are always negative and strong outside the tropics, well offsetting positive feedbacks in most regions and resulting in undercompensation. Different dominant feedbacks give different BJC scenarios at different regions, acting together to maintain the local energy balance.

Keywords Energy conservation - Climate feedback · Bjerknes compensation - Atmosphere heattransport . Ocean heat transport $\cdot$ Coupled model

\section{Introduction}

The energy balance of the Earth's climate system is maintained by meridional heat transports (MHTs) in both ocean and atmosphere, which jointly transport peak energy of about 5.5 PW $\left(1 \mathrm{PW}=10^{15} \mathrm{~W}\right)$ poleward (e.g., Trenberth and Caron 2001; Wunsch 2005). Both atmosphere heat transport (AHT) and ocean heat transport (OHT) can vary on multiple timescales, but their variations tend to be out of phase on decadal and longer timescales based on coupled model studies (e.g., Shaffrey and Sutton 2006; Swaluw et al. 2007; Farneti and Vallis 2013). As a result, the combined variation in the total MHT is small. This scenario was first proposed by Bjerknes (1964) and has become known as the Bjerknes compensation (BJC).

The BJC has been confirmed to be valid by many studies, in models ranging from simple energy balance models (EBMs; e.g., Lindzen and Farrell 1977; Stone 1978; North 1984; Langen and Alexeev 2007; Rose and Ferreira 2013; Liu et al. 2016) to complex climate models (e.g., Clement and Seager 1999; Shaffrey and Sutton 2006; Cheng et al. 2007; Swaluw et al. 2007; Kang et al. 2008, 2009; Vellinga and Wu 2008; Donohoe and Battisti 2012; Farneti and Vallis 2013; Rose and Ferreira 2013; Yang et al. 2013; 
Seo et al. 2014; Yang and Dai 2015). The BJC can occur in internal climate variability (e.g., Shaffrey and Sutton 2006) and in climate responses to external forcing (e.g., Vellinga and Wu 2008; Rose and Ferreira 2013; Yang and Dai 2015). It varies widely among models, in terms of timescales and latitudes. It is measured by the BJC rate, which is defined as the ratio of anomalous AHT to anomalous OHT.

The fundamental mechanism of BJC has been revealed recently in the theoretical studies of Liu et al. (2016) and Yang et al. (2016a). In their conceptual models, the BJC rate was obtained theoretically. It was found to be determined by local climate feedback, that is, the gross linear regression of the net TOA heat flux on the surface temperature. The local climate feedback can be positive, zero or negative. In fact, AHT can perfectly compensate OHT in the absence of local climate feedback, or undercompensate OHT if climate feedback is negative everywhere, or overcompensate OHT in the presence of positive local climate feedback. Their theoretical studies provide explanations for different BJC behaviours in various modelling studies (e.g., Kang et al. 2008, 2009; Vellinga and Wu 2008; Enderton and Marshall 2009; Vallis and Farneti 2009; Zhang et al. 2010; Farneti and Vallis 2013; Yang et al. 2013; Seo et al. 2014). Furthermore, their studies exhibit that the energy conservation forces the out-of-phase changes in AHT and OHT; in other words, the energy conservation determines whether the BJC would occur or not. Violation of energy conservation of climate system could result in the failure of BJC (Yang et al. 2016a). The local climate feedback determines the magnitude of $\mathrm{BJC}$ rate, that is, how the BJC would occur. However, in a coupled Earth system, it is not clear at all whether the constraint of energy balance plays a role in the BJC. Furthermore, there is no study on how the BJC is related to the local climate feedback in a coupled system.

In a series of wind-perturbation experiments using a coupled climate model, we find that the BJC works very well in the mid and low latitudes when the ocean surface wind stress is perturbed. Both the wind-driven and thermohaline overturning circulations are weakened significantly in response to reduced surface winds. The tropical (extratropical) oceans are warmed (cooled) due to the weakening of poleward OHT. The atmospheric Hadley Cell and eddy activities are thus enhanced and transport more atmosphere heat poleward, compensating the decreased OHT. The BJC can be well understood from the view point of large-scale circulation changes. However, the intrinsic mechanism of BJC in a coupled system has not been explored in previous studies. In this paper we focus on the analyses of regional energy balance and climate feedbacks in a coupled climate model, and delve into the intrinsic connections among the BJC, local climate feedback and local energy balance.

Consistent with the theoretical studies of Liu et al. (2016) and Yang et al. (2016a), we confirm that in a coupled system the energy constraint indeed determines the occurrence of the BJC, and that the local climate feedback determines how the BJC occurs. Different compensation scenarios in different regions are due to different local climate feedbacks. We find that no matter the climate responses in these sensitivity experiments, the BJC that occurs in the coupled model satisfies the constraint of energy conservation. This paper is organized as follows. The coupled model and perturbation experiments are introduced in Sect. 2. We describe the equilibrium responses in sensitivity experiments briefly and define the BJC in the coupled model in Sect. 3. We investigate the energy balance and climate feedbacks in a regional box in detail in Sect. 4. Summary and discussion are given in Sect. 5. Detailed calculations of climate feedback related to various physical processes are presented in the "Appendix".

\section{Model and experiments}

The model used in this study is the Community Earth System Model (CESM) version 1.0 of the National Center for Atmospheric Research (NCAR). CESM is a fully coupled global climate model that provides state-of-the-art simulations of the Earth's past, present and future climate states (http://www2.cesm.ucar.edu/). CESM1.0 consists of five components and one coupler: the Community Atmosphere Model (CAM5; Park et al. 2014), the Community Land Model (CLM4; Lawrence et al. 2012), the Community Ice CodE (CICE4; Hunke and Lipscomb 2008), the Parallel Ocean Program (POP2; Smith et al. 2010), the Community Ice Sheet Model (Glimmer-CISM) and CESM Coupler (CPL7). CESM1.0 has been widely used and validated by the researchers in the community (http://journals.ametsoc. org/page/CCSM4/CESM1).

The model grid employed in this study is T31_gx3v7. The CAM5 has 26 vertical levels, with the finite volume nominal $3.75^{\circ} \times 3.75^{\circ}$ in the horizontal. It is essentially a new atmospheric model with more realistic formulations of radiation, boundary layer and aerosols (Meehl et al. 2013; Neale et al. 2013). The general features of the model formulation were given by Neale et al. (2010) and Park et al. (2014). The CLM4 has the same horizontal resolution as the CAM5. The POP2 uses the grid gx $3 v 7$, which has 60 vertical levels. The horizontal grid has a uniform $3.6^{\circ}$ spacing in the zonal direction. In the meridional direction, the grid is non-uniformly spaced: it is $0.6^{\circ}$ near the equator, gradually increasing to the maximum $3.4^{\circ}$ at $35^{\circ} \mathrm{N} / \mathrm{S}$ and then decreasing poleward. The model physics is described in details in Danabasoglu et al. (2012). The CICE4 has the same horizontal grid as the POP2. No flux adjustments are used in CESM1.0.

Experiments analysed in this study include a 2000-year control run (CTRL) and three 500-year wind perturbation 

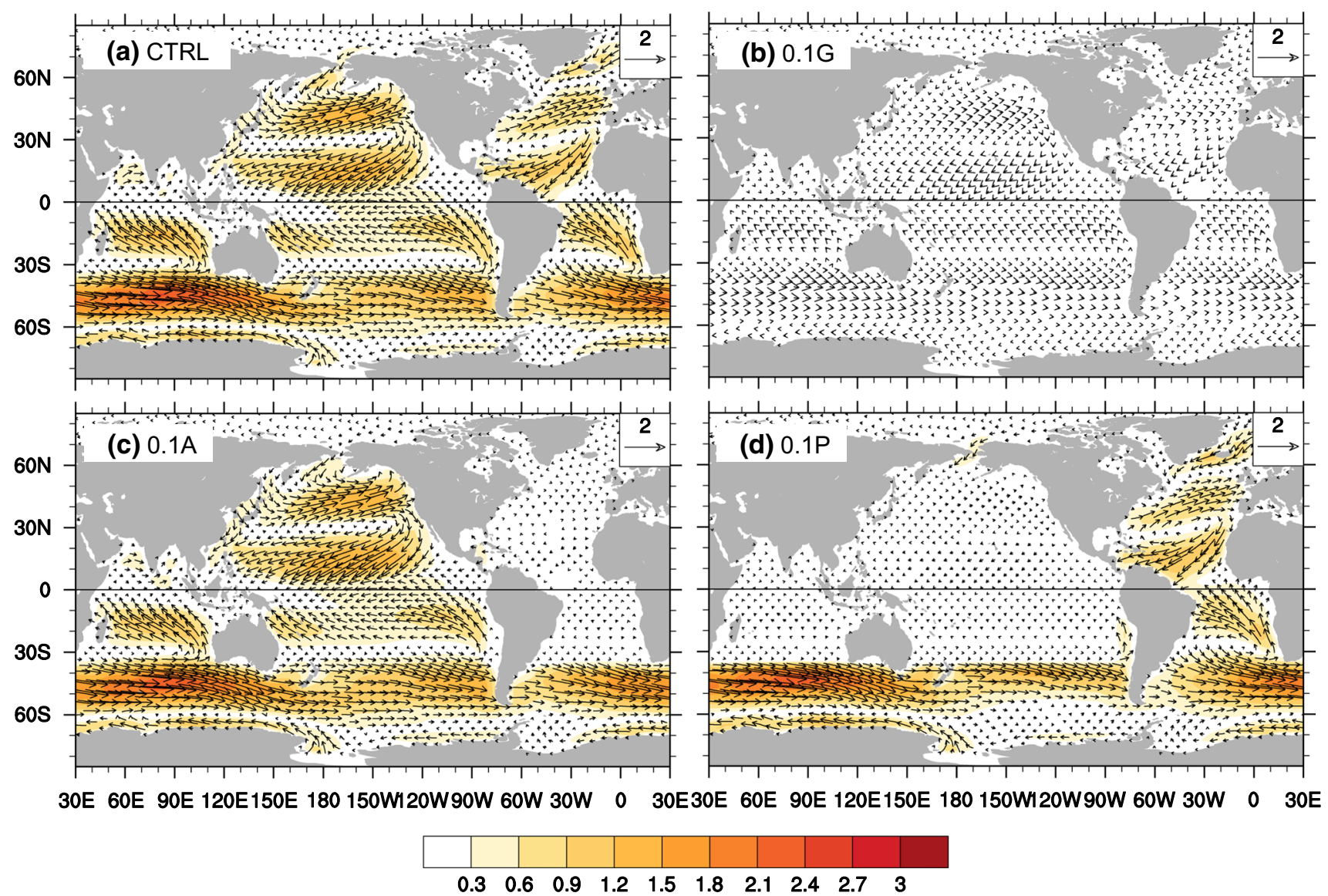

Fig. 1 Wind stress forcing over the ocean (units: dyn $/ \mathrm{cm}^{2}$ ) in a CTRL, b $0.1 \mathrm{G}, \mathbf{c} 0.1 \mathrm{~A}$, and $\mathbf{d} 0.1 \mathrm{P}$. Shading indicates the magnitude of wind stress. Annual-mean wind forcing is plotted to demonstrate the configuration of sensitivity experiments

runs. The CTRL starts from the rest with standard configurations (http://www.cesm.ucar.edu/experiments/cesm1.0/). The model climate as a whole reaches quasi-equilibrium after 1000 years of integration (Yang et al. 2015a). In the wind-perturbation runs, the surface wind stress in the ocean model is multiplied by a factor of 0.1 (Fig. 1a) over the global ocean $(0.1 \mathrm{G}$; Fig. 1b), the Atlantic Ocean (0.1A; Fig. 1c) or the Indo-Pacific Ocean (0.1P; Fig. 1d), while the wind forcing for the ice model remains the same as in the CTRL. The winds in the atmosphere model are not changed artificially, but will change in response to the sea surface temperature (SST) change. The wind experiments are "parallel" to the CTRL during years 1501-2000, namely, using the same initial conditions at the end of year 1500 , and reach quasi-equilibrium after 500-year integration. The monthly-mean outputs are used for analysis. The climate changes in the wind runs are obtained by subtracting the corresponding states in the CTRL. In this study, we focus on the equilibrium responses using the averaged fields over the last 200-year integration, unless stated otherwise.

\section{Equilibrium responses}

\subsection{Energy balance at the TOA}

The changes in shortwave (SW) and longwave (LW) at the TOA in the sensitivity experiments are less than $10 \%$ of their corresponding total values (Fig. 2). The net radiation flux change (SW-LW) is even smaller because of the opposite changes between SW and LW. Figure 2 shows the zonally-averaged radiation flux in CTRL and their changes in the sensitivity experiments. At most latitudes, the opposite changes between SW and LW are nearly perfect (Fig. 2b), leaving the net radiation flux roughly unchanged. In the tropics, the opposite changes in SW and LW are caused by the shift of the intertropical convergence zone (ITCZ) (Yang and Dai 2015). In mid and high latitudes, the reduced outgoing LW (positive change) is caused by lower SST, while the reduced downward SW (negative change) results from an increase in stratus clouds and planetary albedo related to sea ice (Yang and Dai 2015). In general, if we integrate the net radiation flux over the globe, the total 

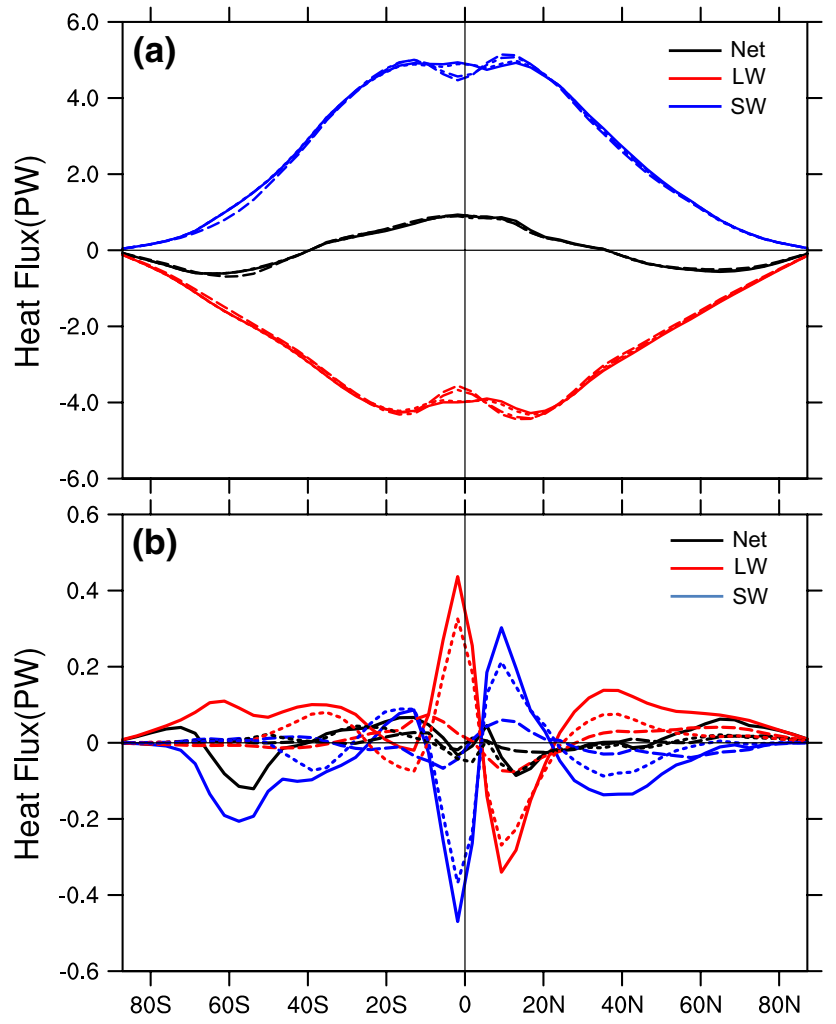

Fig. 2 a The net radiation flux (black), net downward SW (blue) and net outgoing LW (red) at the TOA. Solid, dashed, dotted, and dot-dashed curves are for CTRL, $0.1 \mathrm{G}, 0.1 \mathrm{~A}$, and $0.1 \mathrm{P}$, respectively. b The changes of the TOA net radiation flux in the wind-perturbation experiments. Black, blue and red curves are for changes in the net total, SW and LW, respectively. Solid, dashed and dotted curves for the $0.1 \mathrm{G}, 0.1 \mathrm{~A}$ and $0.1 \mathrm{P}$, respectively. The mean values from the CTRL have been subtracted. The radiation flux has been converted to radiation heat transport by multiplying the surface area of each latitude band, for a better comparison with later figures. Units: PW (1 $\mathrm{PW}=10^{15} \mathrm{~W}$ )

energy change is nearly zero for all three experiments. Figure 2 demonstrates that the global energy conservation in the wind-perturbation experiments is well satisfied.

\subsection{Changes in MHT and MOC}

The equilibrium Earth is maintained by the antisymmetric MHT, with the peak poleward transport occurring around $40^{\circ} \mathrm{N} / \mathrm{S}$ (Fig. 3a). The AHT dominates the MHT poleward of about $10^{\circ} \mathrm{N} / \mathrm{S}$, while the OHT dominates in the deep tropics. These features are consistent with previous studies (e.g., Trenberth and Caron 2001). In the wind-perturbation experiments, significant changes occur in both AHT and OHT (Fig. 3b-d), with the peak change of around 1.4 $\mathrm{PW}, 0.4 \mathrm{PW}$ and $1.0 \mathrm{PW}$ in experiments $0.1 \mathrm{G}, 0.1 \mathrm{~A}$ and $0.1 \mathrm{P}$, respectively. In all wind-perturbation experiments, the changes in OHT and AHT are out of phase, leaving the total MHT change insignificant. Here, we would like to emphasize that the OHT and AHT in Fig. 3 are calculated directly from the VT approach (Yang et al. 2015a), instead of indirectly using the heat flux budgets at the ocean surface and at the TOA. This assures the independence of AHT and OHT. Figure $3 \mathrm{~b}-\mathrm{d}$ shows that the BJC is valid at almost all latitudes for all three wind-perturbation experiments. In fact, the overall BJC rate in these experiments can be simply quantified as follows (Zhao et al. 2016),

$C_{R} \equiv r \frac{\sigma_{F_{a}}}{\sigma_{F_{o}}}$,

where $r$ is the correlation coefficient between AHT and OHT over the whole latitudes; $\sigma_{F_{a}}$ and $\sigma_{F_{o}}$ are standard deviations of AHT and OHT, respectively, with respect to latitudes. Only negative correlation $(r<0)$ suggests a compensation, and the degree of BJC is determined by both the correlation and the ratio of the standard deviations of AHT and OHT. If correlation is very low $(r \rightarrow 0)$, there will be no meaningful compensation. Of course, positive correlation $(r \geq 0)$ suggests no compensation.

In general, the AHT change undercompensates the OHT change in the wind-perturbation experiments. The overall BJC rate is around -0.85 for all experiments. The overall undercompensation (i.e., $\left|C_{R}\right|<1$ ) suggests an overall negative climate feedback for the whole Earth's system (Yang et al. 2016a). The latter is obvious because it is required by the stable Earth. However, this method cannot tell the different compensation in different latitudes. The regional compensation is closely related to the local climate feedback between the surface temperature and the net radiation flux at the TOA, as investigated in our conceptual coupled model (Yang et al. 2016a).

The out-of-phase changes in AHT and OHT in the windperturbation experiments are consistent with changes in the atmospheric and oceanic meridional overturning circulations (MOC) (Fig. 4). In addition to the STC and AMOC, Antarctic Bottom Intermediate Water seems to be also significantly reduced. In the $0.1 \mathrm{G}$ run, both Indo-Pacific subtropical cell (STC) and Atlantic MOC (AMOC) are weakened significantly (Fig. $4 \mathrm{~b}$ ) as a result of reduced wind stress over the global ocean. The OHT decreases at nearly all the latitudes (blue curves, Fig. 3b), resulting in warming in the tropics and cooling in higher latitudes (Fig. 5a) and stronger poleward SST gradient. In response to the SST change, the atmospheric Hadley Cell is strengthened (Fig. 4f), so are the eddy activities in mid and high latitudes. Therefore, the poleward AHT is increased at almost all latitudes (red curves, Fig. 3b), compensating for the decreased OHT. The detailed mechanisms for ocean and atmosphere MOC changes in response to wind perturbation were investigated in Yang and Dai (2015) and Yang et al. (2016b). In the $0.1 \mathrm{~A}$ run, the AMOC is shut down, and the Indo-Pacific STC is hardly changed (Fig. 4c). 

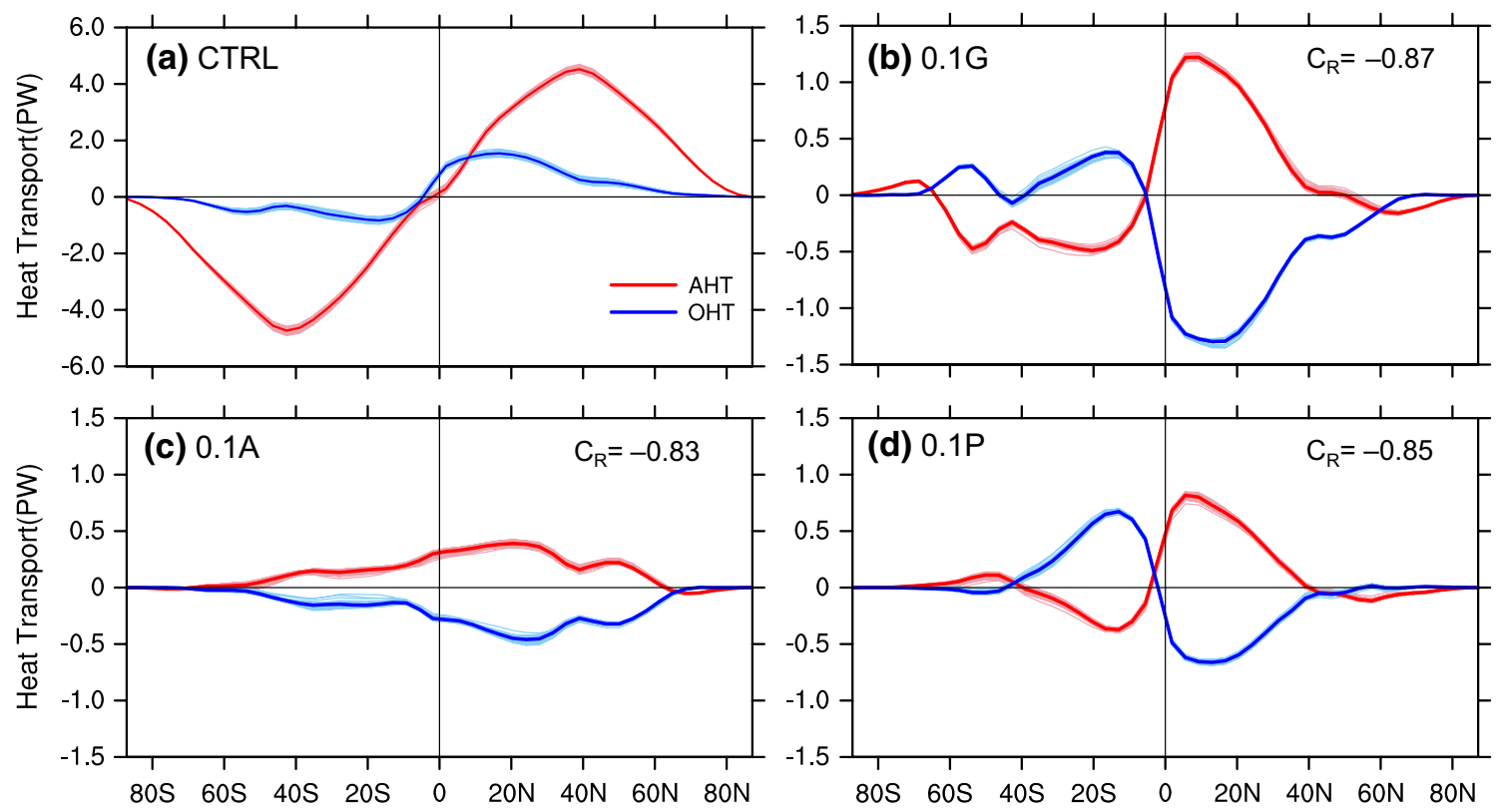

Fig. 3 The AHT (red) and global total OHT (blue) in a CTRL and their changes in b $0.1 \mathrm{G}, \mathbf{c} 0.1 \mathrm{~A}$ and $\mathbf{d} 0.1 \mathrm{P}$. Units: PW. In these plots, the solid heavy curves represent 200-year-mean values; the light color curves are for individual years, but smoothed with an 11-year running mean filter. The light colors show qualitatively the spread of each variable at decadal and longer timescales, giving an error bar of about $0.02 \mathrm{PW}$. The overall $\mathrm{BJC}$ rates are $-0.87,-0.83$ and -0.85 for $0.1 \mathrm{G}, 0.1 \mathrm{~A}$ and $0.1 \mathrm{P}$, respectively (a) Ctrl
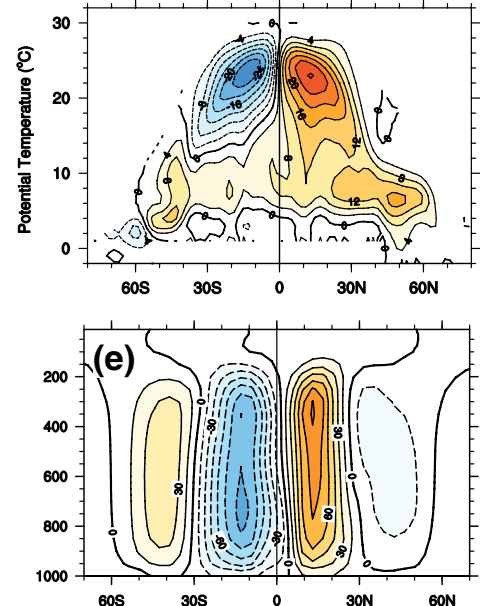

(b) $0.1 \mathrm{G}$

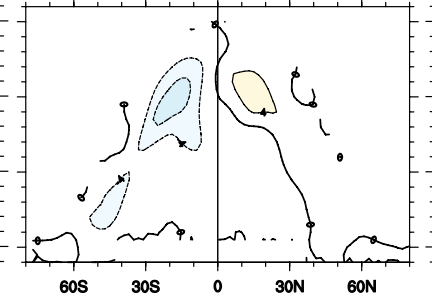

(c) $0.1 \mathrm{~A}$

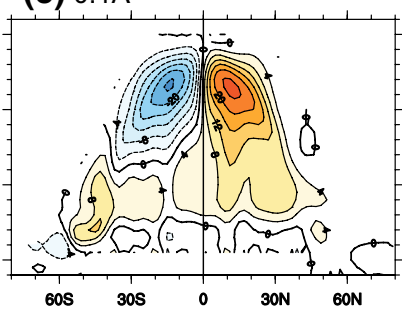

(d) $0.1 \mathrm{P}$
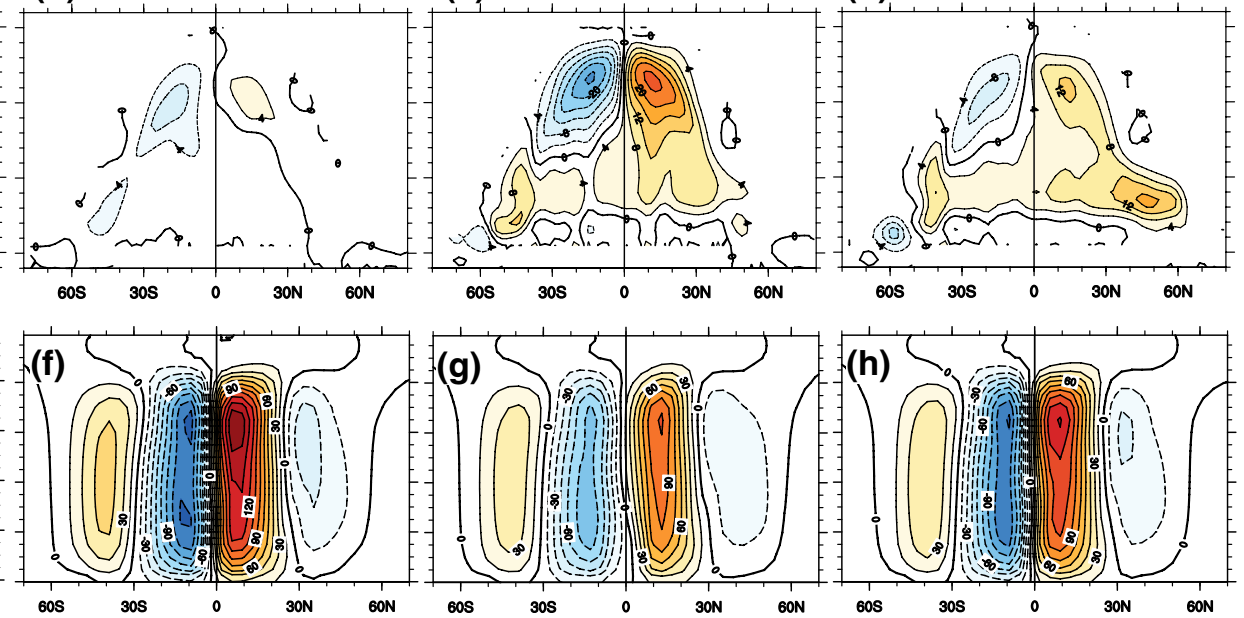

Fig. 4 Upper panels The global-mean ocean MOC in a CTRL, b $0.1 \mathrm{G}, \mathbf{c} 0.1 \mathrm{~A}$, and d $0.1 \mathrm{P}$. Units: $\mathrm{Sv}\left(1 \mathrm{~Sv}=10^{6} \mathrm{~m}^{3} / \mathrm{s}\right)$. Lower panels The mean atmosphere meridional mass streamfunction in e CTRL, $\mathbf{f}$
$0.1 \mathrm{G}, \mathbf{g ~} 0.1 \mathrm{~A}$, and h $0.1 \mathrm{P}$. Units: $10^{9} \mathrm{~kg} / \mathrm{s}$. The vertical coordinate for the lower panels is pressure in $\mathrm{hPa}$

The SST warming occurs mainly in the Pacific, resulting in an intensified Hadley Cell (Fig. 4h). Both OHT and AHT show antisymmetric changes with respect to the equator in the Indo-Pacific (Fig. 3d). We see that the changes in the $0.1 \mathrm{G}$ (Figs. 3b, 4b, f, 5a) are nearly linear superimposition of the changes in the $0.1 \mathrm{~A}$ (Figs. 3c, 4c, g, 5b) and in the 0.1P (Figs. 3d, 4d, h, 5c), except in the Southern Ocean. shut down, while the AMOC is hardly changed (Fig. 4d). 
(a) $0.1 \mathrm{G}$

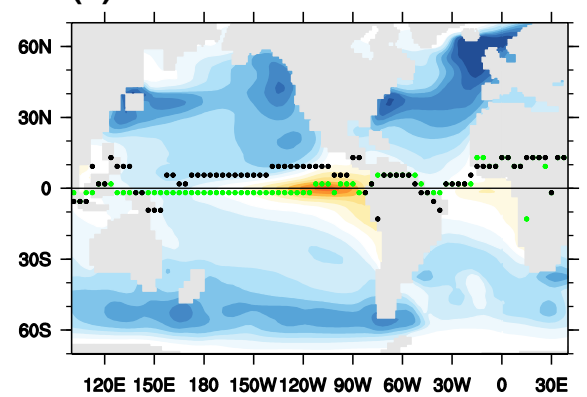

(b) $0.1 \mathrm{~A}$

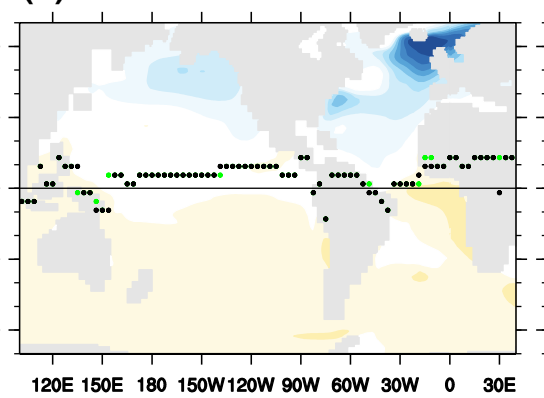

(c) $0.1 \mathrm{P}$

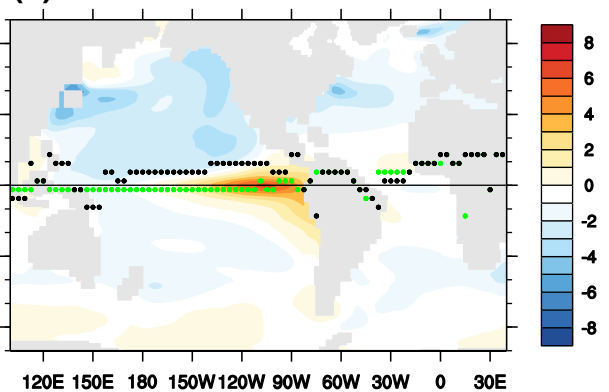

Fig. 5 The change in global-mean SST (units: ${ }^{\circ} \mathrm{C}$ ) in a $0.1 \mathrm{G}, \mathbf{b} 0.1 \mathrm{~A}$ and $\mathbf{c} 0.1 \mathrm{P}$. The black and green dots represent the location of the ITCZ, which is defined as the location of the maximum convergence of surface winds near the equator. The black dots represent the ITCZ in CTRL, and the green dots, in the wind-perturbation experiments

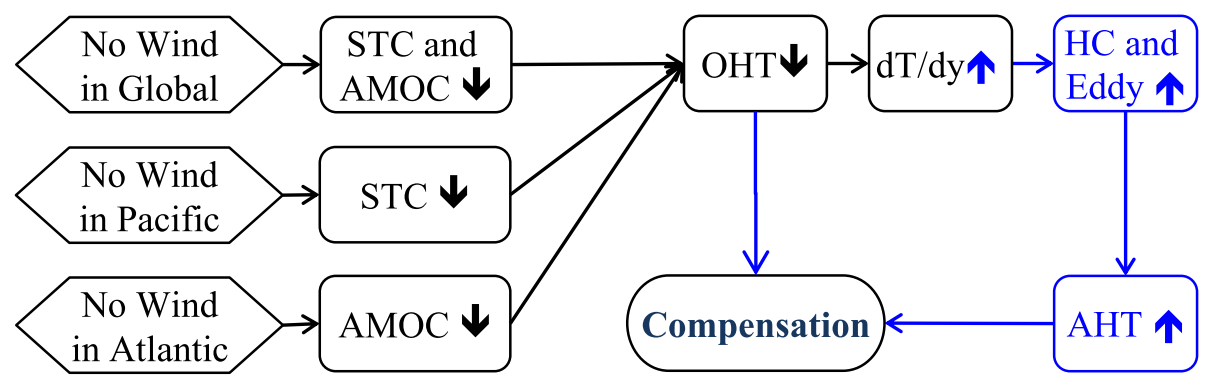

Fig. 6 Schematic diagram showing the main processes that are responsible for the compensation between the changes in AHT and OHT. The upward (downward) arrows represent increase (decrease).
STC: the Subtropical Cell; AMOC: the Atlantic MOC; HC: the Hadley Cell; OHT (AHT): the ocean (atmosphere) heat transport. dT/dy represents the meridional SST gradient
We also see that the ITCZ shift occurs mainly in the Pacific (Fig. 5a, c), in response to the Indo-Pacific wind-driven circulation change.

In general, the climate system can exhibit the BJC clearly when the winds are perturbed over the oceans. The main processes in response to wind changes are summarized in Fig. 6. Although different perturbations result in different response patterns, the $\mathrm{BJC}$ is always valid and the $\mathrm{BJC}$ rate is more or less the same. It is plausible that the BJC can be well understood from the view point of large-scale circulation changes. Questions remain though, such as what determines the degree of BJC in a coupled system, and why there are outof-phase changes in AHT and OHT to maintain local energy balance, since in principal any local energy imbalance can be damped locally in the vertical direction through negative climate feedback between the energy flux at the TOA and surface temperature. More insightful understanding of the BJC mechanism in a coupled Earth system is needed.

\section{Energy balance and climate feedback}

The constraint of global energy conservation is critical to the occurrence of BJC (Bjerknes 1964). This hypothesis was investigated in a conceptual coupled box model (Yang et al. 2016a). Theoretically the BJC rate at the latitude boundary in a two-box system is formulated as:

$C_{R} \equiv \frac{\Delta F_{a}}{\Delta F_{o}}=-\frac{1}{1-B_{1} B_{2} /\left[\left(B_{1}+B_{2}\right) \chi\right]}$.

Equation (2) explicitly states that $C_{R}$ is independent of the mean climate, changes in temperature and salinity, as well as the heat transports themselves. It is determined by only climate parameters: the local climate feedback parameters $B_{i}$, and the AHT coefficient $\chi$. Here, $\Delta F_{a}$ and $\Delta F_{o}$ are anomalous AHT and OHT, respectively. The local climate feedback $B_{i}$ can be roughly depicted as the linear regression of the net TOA radiation flux on the surface temperature and can be obtained based on observational data (Rose and Marshall 2009; Yang et al. 2015b). $\chi$ represents the efficiency that the AHT changes in response to the meridional surface temperature contrast, which can be also diagnosed based on observational data (North 1975; Yang et al. $2015 b$ ). In a stable climate system, $B_{i}<0$ usually, representing an overall negative climate feedback; therefore, $C_{R}$ is always negative $\left(C_{R}<0\right)$, or the changes in AHT and OHT always compensate each other. Since $\chi$ is always positive and less uncertain (North 1975; Marotzke and Stone 


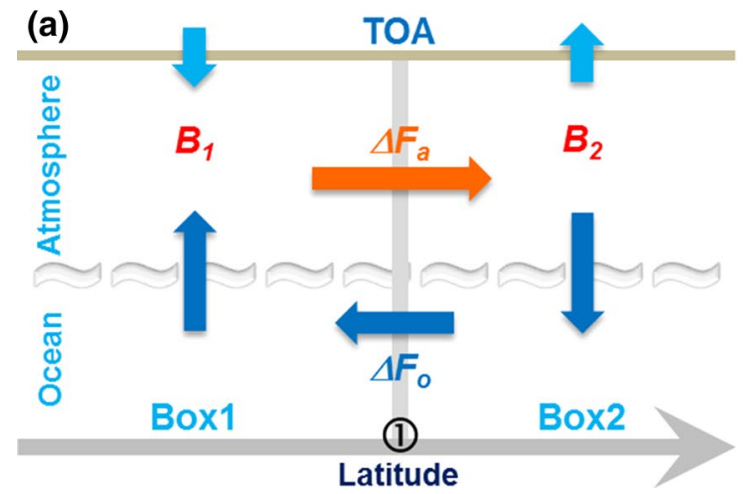

Fig. 7 Schematic diagram showing the BJC mechanism. The energy is conserved for each atmosphere and ocean box. The horizontal arrows represent the anomalous heat transport across the latitude boundary $(1,2)$ of ocean-atmosphere box; the vertical arrows represent the anomalous heat flux at the ocean surface and the TOA. $\Delta \mathrm{F}_{\mathrm{a}}$ and $\Delta \mathrm{F}_{\mathrm{o}}$ represent anomalous AHT and OHT. $B_{1}, B_{2}, B_{3}$ represent cli-

1995; Yang et al. 2015b), we will focus on $B_{i}$ in this paper, which can be positive, zero or negative.

Figure 7a shows conceptually how the energy balance at the TOA and the climate feedback determine the BJC at the box boundary (Latitude-1) in a two-box system. To better understand $\mathrm{BJC}$, one can imagine two extreme scenarios. First, if the local climate feedback is zero $\left(B_{1}\right.$ or $\left.B_{2}=0\right)$, that is, the net heat flux change at the TOA for a regional box is strictly zero regardless of the surface temperature change, all energy anomalies in the atmosphere have to be transported horizontally, that is, the AHT will perfectly compensate the OHT $\left(\Delta F_{a}=\Delta F_{o},\left|C_{R}\right|=1\right)$. Second, if the local negative climate feedback is extremely strong, any local heat imbalance will be effectively damped locally and there will be no need for AHT change $\left(B_{1,2} \rightarrow \infty,\left|C_{R}\right| \rightarrow 0\right)$, that is, there is no BJC. In common cases, the climate feedbacks are not zero $\left(B_{1}, B_{2} \neq 0\right)$ and the relative change of $\Delta F_{a}, \Delta F_{o}$ at the latitude boundary in a two box system is determined by the net heat flux at the TOA, which is, in turn, determined by the climate feedback in the two boxes (Fig. 7a). So that climate feedback plays the most critical role in the energy balance for a regional box. Moreover, the climate feedback can be positive or negative, which can result in overcompensation $\left(\left|C_{R}\right|>1\right)$ or undercompensation $\left(\left|C_{R}\right|<1\right)$. Equation (2) actually provides theoretical explanations for different BJC behaviours in various modelling studies (e.g., Kang et al. 2008, 2009; Vellinga and Wu 2008; Enderton and Marshall 2009; Vallis and Farneti 2009; Zhang et al. 2010; Farneti and Vallis 2013; Yang et al. 2013; Seo et al. 2014).

In a three-box system as shown in Fig. 7b, the BJC at latitude boundaries ( 1 and 2) can be also obtained based on Eq. (2). In fact the three-box system can be reduced to the two-box system. For example the BJC at latitude-1 is

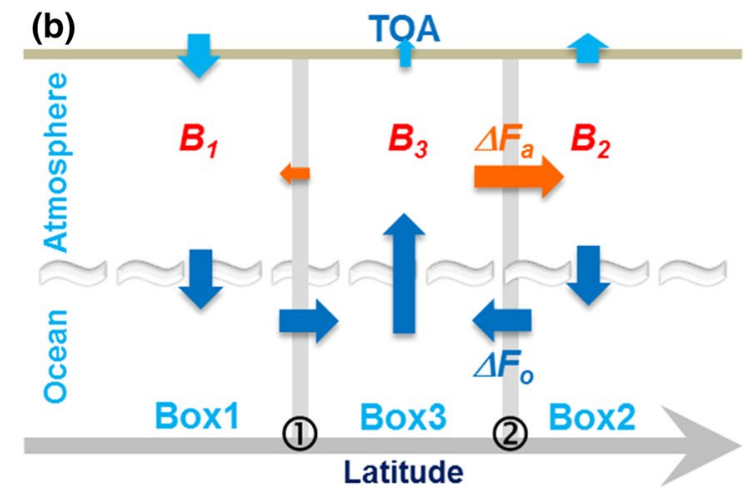

mate feedback in regional box, depicting roughly the linear regression of the net heat flux at the TOA on the surface temperature. a A two-box situation, the BJC at latitude- 1 is determined by the climate feedback $B_{1}$ and $B_{2}$ as formulated in Eq. (2). b A three-box situation, the BJC at latitude-1 (or 2) is determined by $B_{1}\left(B_{2}\right)$ and the mean of $B_{2}+B_{3}\left(B_{1}+B_{3}\right)$. In fact the situation (b) can be reduced to (a)

determined by $B_{1}$ in Box- 1 and the mean of $B_{2}+B_{3}$ (Box-2 and Box-3). Same rule can be applied to the BJC at latitude-2. For Box-3 alone, the energy balanced is determined by $\Delta F_{a}, \Delta F_{o}$ at two latitude boundaries and the net heat flux at the TOA. The climate feedback $B_{3}$ in this box is insufficient to determine the BJC at two boundaries.

Here we will use the two-box conceptual model and Eq. (2) to understand the roles of local energy conservation and climate feedback in the BJC in a complex coupled model. Before doing so, first we need to identify local climate feedbacks in the coupled system, which are obtained in this study using a so-called "Radiative Kernel Technique" (Shell et al. 2008; Soden et al. 2008; Jonko et al. 2012; Zelinka and Hartmann 2012). Please refer to the "Appendix" for detail approach and feedback patterns in different experiments (Figs. 13, 14, 15). Second, to easily illustrate the BJC at different latitudes for the coupled model sensitivity experiments, a simpler and more practical way is used:

$\Delta F_{t} \equiv\left|\Delta F_{a}\right|-\left|\Delta F_{o}\right|$,

where $\Delta F_{t}$ is the change in the total MHT, with respect to the control run. Positive, zero or negative $\Delta F_{t}$ represents that the AHT overcompensates, perfectly compensates or undercompensates the OHT, respectively. Here, we define that $\Delta F_{t}$ has a valid value only when $\Delta F_{a}$ and $\Delta F_{o}$ have different signs. $\Delta F_{t}$ can show different BJC scenarios at different latitudes as in Fig. 3, since it is a function of latitude.

To discuss the regional energy balance and regional climate feedback in the coupled model sensitivity experiments, regional boundaries need to be set first. We would like to emphasize that the boundary selection can be arbitrary along any latitude circle. For any given regional box, 
the energy should be balanced in an equilibrium state as illustrated in Fig. 7. For an atmosphere box, the energy budget consists of heat fluxes from the (ocean and land) surface and the TOA, as well as the meridional AHT across selected latitude boundaries. For an ocean box, the energy budget consists of heat fluxes across the ocean surface and the meridional OHT across selected latitudes.

\subsection{Energy balance and climate feedback in $0.1 \mathrm{~A}$}

Energy budget in the 0.1A run is illustrated in Fig. 8. The meridionally-integrated energy changes at the TOA (Fig. 8a) and the ocean surface (Fig. 8c) are nearly zero. The total energy of the Earth system is conserved. At the TOA, the change in the net heat flux (downward SW minus upward LW) is significant in the Northern Hemisphere (NH) (Fig. 8a), consistent with the significant changes in net surface heat flux and surface temperature in the North Atlantic (Fig. 8c, d). In Fig. 8, the vertical dashed grey lines outline the regional boxes: the tropical $\mathrm{NH}$ box between $10^{\circ} \mathrm{S}-40^{\circ} \mathrm{N}$, the extratropical $\mathrm{NH}$ box northward of $40^{\circ} \mathrm{N}$ and the Southern Hemisphere (SH) box southward of $10^{\circ} \mathrm{S} . \Delta F_{a}$ and $\Delta F_{o}$ across $10^{\circ} \mathrm{S}$ and $40^{\circ} \mathrm{N}$ are plotted in Fig. $8 \mathrm{~b}$ and $\mathrm{d}$ as thick red and blue arrows, respectively. The net MHT change $\Delta F_{t}$ is plotted in Fig. 8b, showing an overcompensation in the tropics and undercompensation at other latitudes.

For each regional box, the atmosphere energy and ocean energy are well balanced within the error bar $( \pm 0.02 \mathrm{PW}$, which is estimated as one standard deviation of MHT based on Fig. 3b-d). In the extratropical NH box, the atmosphere undercompensates the ocean by about $0.1 \mathrm{PW}$ at $40^{\circ} \mathrm{N}$ (Fig. 8b). The anomalous OHT across $40^{\circ} \mathrm{N}$ is about $0.28 \mathrm{PW}$ equatorward (Fig. 8d), in response to the weakened AMOC. To maintain the ocean energy balance, the ocean gain about $0.28 \mathrm{PW}$ through the surface by reducing latent heat loss (Fig. 8c) in association with the surface cooling. On the other hand, the surface ocean cooling also results in less outgoing LW at the TOA (Fig. 8a), which can partially offset the atmosphere heat loss (to the ocean). The remaining energy needed to maintain the atmosphere energy balance has to rely on the northward AHT, which is about $0.18 \mathrm{PW}$ across $40^{\circ} \mathrm{N}$ (Fig. 8b). We can see that the AHT undercompensates the OHT because the atmosphere does not need exactly $0.28 \mathrm{PW}$ energy from low latitudes, and part of its energy loss can be made up by the energy gained at the TOA $(0.12 \mathrm{PW})$, which is in turn due to overall negative feedback between the surface temperature and the net heat flux at the TOA.

Similar analysis on the energy balance for the other boxes can be made as follows. In the tropical box, the ocean transports $0.14 \mathrm{PW}$ out of the tropical region across $10^{\circ} \mathrm{S}$ but gains $0.28 \mathrm{PW}$ at $40^{\circ} \mathrm{N}$ (Fig. $8 \mathrm{~d}$ ). The net energy gain due to OHT is about $0.14 \mathrm{PW}$, which has to be exported to the atmosphere through the ocean surface

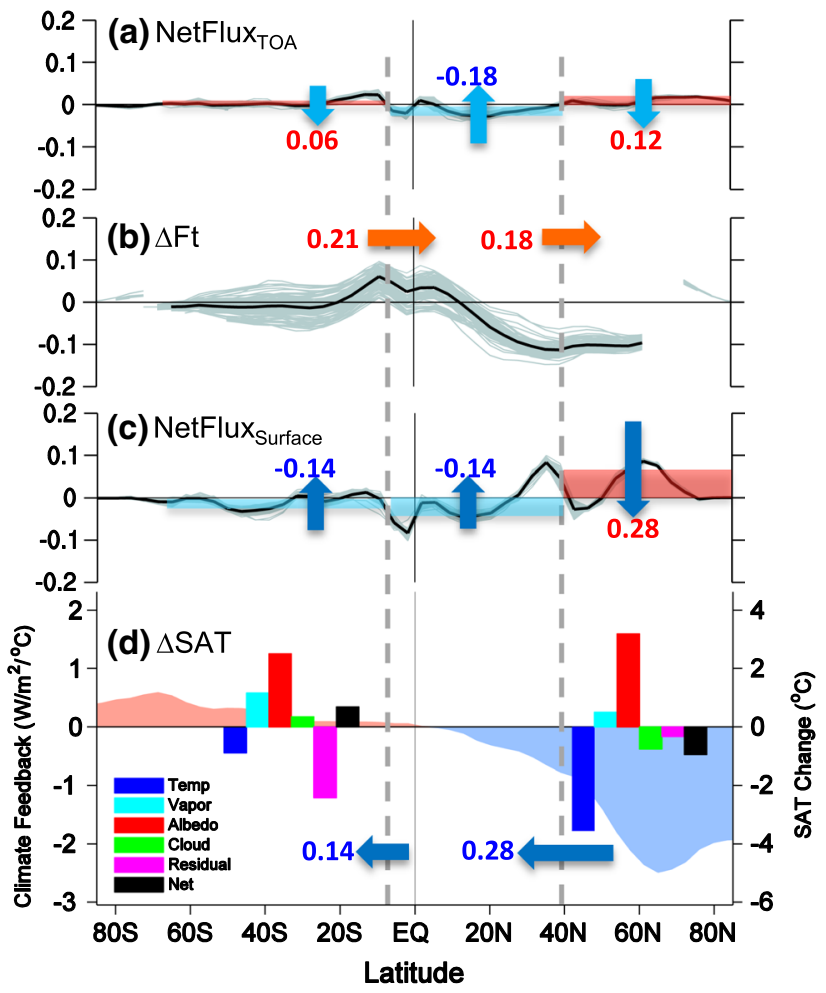

Fig. 8 Energy budget in 0.1A. a The net flux change at the TOA. b The net MHT change $\Delta \mathrm{Ft}$, which is plotted only when $\Delta \mathrm{Fa}$ and $\Delta \mathrm{Fo}$ have different signs. $\mathbf{c}$ The net heat flux change at the ocean surface. d Zonally-averaged surface air temperature change $\left(\Delta \mathrm{SAT},{ }^{\circ} \mathrm{C}\right.$, shade curve). The grey dashed vertical lines show the latitude sections we use to analyze the results. a, c The fluxes $\left(\mathrm{W} / \mathrm{m}^{2}\right)$ have been converted to PW by multiplying the areas for an easy comparison with MHT. a The values show area-integrated outgoing (blue) and incoming (red) energy at the TOA. b Arrows and values show the direction and magnitude of $\Delta \mathrm{Fa}$ across the latitude sections, respectively. $\mathbf{c}$ Values show area-integrated outgoing (blue) and incoming (red) energy at the ocean surface. a-c, Solid thick black curves represent 200-year-mean values; the light grey curves are for individual years, but smoothed with an 11-year running mean filter. The light grey curves show qualitatively the spread of each variable at decadal and longer timescales. d Arrows and numbers show the direction and magnitude of $\Delta \mathrm{F}_{\mathrm{o}}$ across the latitude sections, respectively. Note that all the values have an error bar of $\pm 0.02 \mathrm{PW}$, within which the energy for each regional box is conserved. The color bars in $\mathbf{d}$ show the mean climate feedbacks (unit: $\mathrm{W} / \mathrm{m}^{2} /{ }^{\circ} \mathrm{C}$ ) averaged within $80^{\circ} \mathrm{S}-10^{\circ} \mathrm{S}$ (left cluster) and $40^{\circ} \mathrm{N}-80^{\circ} \mathrm{N}$ (right cluster), respectively, which are obtained by dividing the area-mean heat flux (in $\mathrm{W} / \mathrm{m}^{2}$ ) by area-mean $\Delta$ SAT. Different color bars represent climate feedbacks by different processes shown in Eq. (4) "Appendix". The positive (negative) value represents positive (negative) climate feedback

(Fig. 8c). This is accomplished by reducing the SW gain at the surface, which results from more stratus cloud (figure not shown). For the atmosphere box, the vertical heat imbalance is about $0.04 \mathrm{PW}$. This is balanced by the net heat gain $(0.03 \mathrm{PW})$ from horizontal AHT. The heat loss at the TOA (Fig. 8a) is $0.18 \mathrm{PW}$, more than the 0.14 PW gained heat at the ocean surface. There are $0.21 \mathrm{PW}$ 
incoming AHT across $10^{\circ} \mathrm{S}$ (Fig. 8b), more than the 0.18 PW outgoing northward AHT across $40^{\circ} \mathrm{N}$. For the SH box, the regional energy for atmosphere and ocean are also balanced, as expected. The ocean gains energy from the southward OHT and loses it all to the atmosphere (Fig. 8d). The atmosphere gains energy from both the lower boundary and the TOA (Fig. 8a, c), which is then transported northward (Fig. 8b). Around $10^{\circ} \mathrm{S}$, the $0.21 \mathrm{PW}$ northward AHT overcompensates the $0.14 \mathrm{PW}$ southward OHT. Here, we see a surface warming but more energy gain at the TOA, suggesting a positive feedback between them in the SH region.

In general, no matter what the regional climate feedback and the energy budget at the TOA are, energy is balanced for every latitude box within the error bar $( \pm 0.02 \mathrm{PW})$. Second, how the AHT compensates the OHT depends on the climate feedback. In particular, the sign of climate feedback is critical to the behaviours of BJC. Detailed climate feedbacks in 0.1A are examined in Fig. 8d (color bars). To understand the undercompensation (overcompensation) of AHT with respect to OHT across $40^{\circ} \mathrm{N}\left(10^{\circ} \mathrm{S}\right)$ (Fig. 8b), we follow the two-box approach illustrated in Fig. 7a. The areamean feedbacks are obtained based on feedback patterns (Fig. 13) in the "Appendix". The mean climate feedbacks are obtained by dividing the area-mean heat flux (in W/ $\mathrm{m}^{2}$ ) (Fig. 13) by area-mean surface air temperature change $\triangle$ SAT. Different color bars represent climate feedbacks by different processes shown in Eq. (4). The positive (negative) value represents positive (negative) climate feedback. The net positive (negative) climate feedback given in black bar explains the overcompensation (undercompensation).

The undercompensation across $40^{\circ} \mathrm{N}$ is due to the overall negative feedback in the extratropical high latitudes (black bar in the right cluster, Fig. 8d). The cooling in this region is partially retarded by the heat gain at the TOA because of the negative feedback. Therefore, to keep the energy balance in this region, the AHT change does not have to be as strong as the OHT change. The strong negative LW feedback (blue bar in the right cluster) related to surface cooling dominates over the strong positive SW feedback related to the surface albedo change by ice increase (red bar), resulting in the overall negative feedback (black bar) there. The feedbacks related to clouds (green bar) and water vapour (cyan bar) are negative and positive, respectively, and they are relatively small and minor.

The overcompensation across $10^{\circ} \mathrm{S}$ is due to the overall positive feedback in the SH (black bar in the left cluster, Fig. 8d). The surface warming in the $\mathrm{SH}$ is enhanced further by the heat gain at the TOA, mainly in the tropics between $30^{\circ} \mathrm{S}-10^{\circ} \mathrm{S}$, due to the positive feedbacks related to the albedo, water vapour and clouds (red, cyan and green bars). Therefore, to keep the energy balance in this region, the AHT change has to be stronger than the OHT change, resulting in an overcompensation. These positive feedbacks are partially offset by the negative feedback of outgoing LW (blue bar). It is seen that the calculation error (magnetic red bar) in this region is relatively big. The origins of the errors are complex and have been discussed in details in Zelinka and Hartmann (2012) (please also refer to the "Appendix"). In the high-latitude region of the SH (southward of $30^{\circ} \mathrm{S}$ ), the overall feedback is nearly neutral, because the net radiative flux change at the TOA is very small (Fig. 8a) $(-0.02$ $\mathrm{PW}$, within the $\pm 0.02 \mathrm{PW}$ error bar), resulting in nearly perfect compensation southward of $30^{\circ} \mathrm{S}$ (Fig. 8b).

The undercompensation (overcompensation) across $40^{\circ} \mathrm{N}$ $\left(10^{\circ} \mathrm{S}\right)$ can be also understood by the overall negative (positive) feedback between the South Pole and $40^{\circ} \mathrm{N}$ (North Pole and $10^{\circ} \mathrm{S}$ ) based on two-box approach in Fig. 7a. Southward of $40^{\circ} \mathrm{N}$, the net heat balance at the TOA is $-0.12 \mathrm{PW}$ (Fig. 8a), corresponding to an overall weak surface warming (Fig. 8d), that is, a strong negative feedback. Northward of $10^{\circ} \mathrm{S}$, the net heat balance at the TOA is $-0.06 \mathrm{PW}$, corresponding to a strong surface cooling, that is, a weak positive feedback. The BJC at $40^{\circ} \mathrm{N}$ and $10^{\circ} \mathrm{S}$ cannot be explained by the feedback within $10^{\circ} \mathrm{S}$ and $40^{\circ} \mathrm{N}$, since one feedback parameter cannot determine the horizontal transports at two latitude boundaries as illustrated in Fig. 7b.

\subsection{Energy balance and climate feedback in 0.1P}

Significant changes in the $0.1 \mathrm{P}$ run occur mainly in low latitudes (Figs. 3d, 5c), in response to the antisymmetric change in the Indo-Pacific subtropical cell (STC) (Fig. 4d). Energy budget change in the $0.1 \mathrm{P}$ run is illustrated in Fig. 9. As expected, the meridionally-integrated energy changes at the TOA and the ocean surface are nearly zero. The total energy of the Earth system is conserved. The BJC is valid here. At the TOA, the change in the net heat flux is significant in low latitudes (Fig. 9a), consistent with the significant changes in the net surface heat flux and SST in the tropics (Fig. 9c, d). In Fig. 9, the vertical dashed grey lines outline the tropical boxes we are concerned. The tropical box focuses on the region between $10^{\circ} \mathrm{S}$ and $20^{\circ} \mathrm{N}$, while the $\mathrm{NH}$ box focuses on the region north of $20^{\circ} \mathrm{N}$. The changes in AHT and OHT across $10^{\circ} \mathrm{S}, 20^{\circ} \mathrm{N}$ and the equator are plotted in Fig. $9 \mathrm{~b}$ and $\mathrm{d}$ as thick red and blue arrows. The net MHT change is plotted in Fig. 9b, showing an undercompensation (overcompensation) south (north) of $5^{\circ} \mathrm{S}$.

Here, we focus on the energy balance in the tropical box, where the ocean gains heat due to the anomalous equatorward OHT $\left(0.6 \mathrm{PW}\right.$ across $10^{\circ} \mathrm{S}$ and $0.65 \mathrm{PW}$ across $20^{\circ} \mathrm{N}$, Fig. 9d), in response to the weakened STC. This ocean heat gain is released into the atmosphere by enhancing outgoing LW and latent heat, as a result of warmer SST (Fig. 5c). The tropical atmosphere gains $1.25 \mathrm{PW}$ from the ocean and then loses it to the extratropics and the outer space (Fig. 9a, b), through anomalous poleward AHT and enhanced 
outgoing LW at the TOA. The former is completed by the enhanced Hadley Cell, and the latter, by the warmer air temperature.

A nearly perfect compensation occurs around $20^{\circ} \mathrm{N}$ (Fig. 9b), which is due to the neutral overall climate feedback averaged over the extratropical NH (black bar in the right cluster, Fig. 9d). The atmosphere (ocean) in the extratropical NH gains (loses) heat only through meridional transport. The net energy change at the TOA is negligible $(0.01$ PW) (Fig. 9a). We can see that the strong negative LW feedback (blue bar) is almost balanced by the positive feedback related to albedo (red bar), clouds (green bar) and water vapour (cyan bar). Across the equator, there is a strong overcompensation ( 0.48 vs. 0.26 PW, Fig. 9b, d). This overcompensation can be understood as a result of overall positive feedback averaged in the NH (black bar in the left cluster, Fig. 9d), based on the two-box approach illustrated in Fig. 7. Since the overall climate feedback north of $20^{\circ} \mathrm{N}$ is neural, the overall positive feedback in the $\mathrm{NH}$ mainly attributes

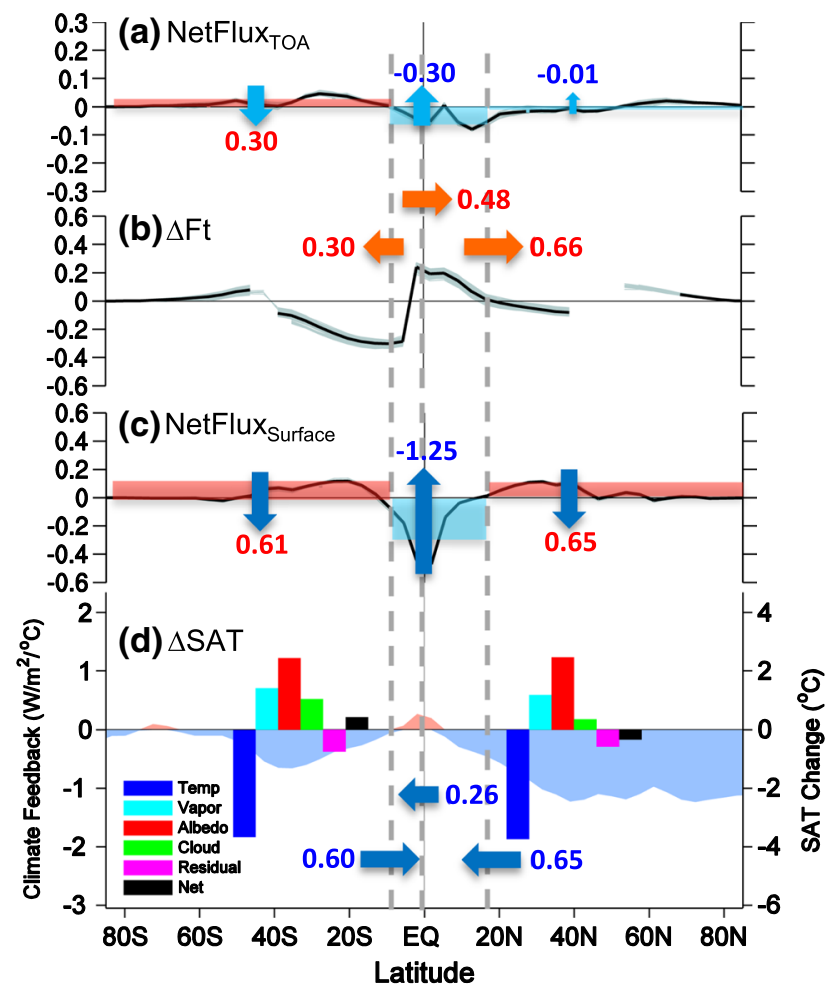

Fig. 9 Same as Fig. 8, except for 0.1P. b The curves for $\Delta \mathrm{Ft}$ show "broken" over certain latitudes because $\Delta \mathrm{Fa}$ and $\Delta \mathrm{Fo}$ have the same signs, suggesting no BJC over there. The bars in $\mathbf{d}$ show the mean climate feedbacks averaged between Equator and $80^{\circ} \mathrm{N}$ (left cluster) and between $20^{\circ} \mathrm{N}$ and $80^{\circ} \mathrm{N}$ (right cluster), respectively. The positive (negative) value represents positive (negative) climate feedback. The net positive climate feedback (left black bar) explains the overcompensation across the equator. The nearly zero net climate feedback (right black bar) explains the nearly perfect compensation across $20^{\circ} \mathrm{N}$ to the strong positive feedback within the tropics, which is predominantly contributed by clouds (green bar) and water vapour (cyan bar), and are in turn resulted from the southward shift of ITCZ (Fig. 5c). The reductions in clouds and water vapour in the tropics result in more outgoing LW loss, playing positive feedbacks in this region so as to drive a strong change in the atmosphere circulation (Fig. 4h) and thus AHT. The feedbacks related to surface albedo and SST in the tropics are negligible. Note the blue and red bar in the left cluster are mainly contributed by those in the right cluster. South of $5^{\circ} \mathrm{S}$, there is an undercompensation, which is due to the overall negative feedback in the SH (bars not shown): the cooling at the surface (Fig. 9d) is retarded by the heat gain at the TOA (Fig. 9a).

\subsection{Energy balance and climate feedback in 0.1G}

The changes in the $0.1 \mathrm{G}$ run are roughly equal to the linear superposition of changes in the $0.1 \mathrm{~A}$ and the $0.1 \mathrm{P}$ runs, except over the Southern Ocean (Figs. 3b-d, 4, 5). The undercompensation in the extratropical NH (Fig. 10b) is attributed mainly to the negative LW feedback, similar to the situation

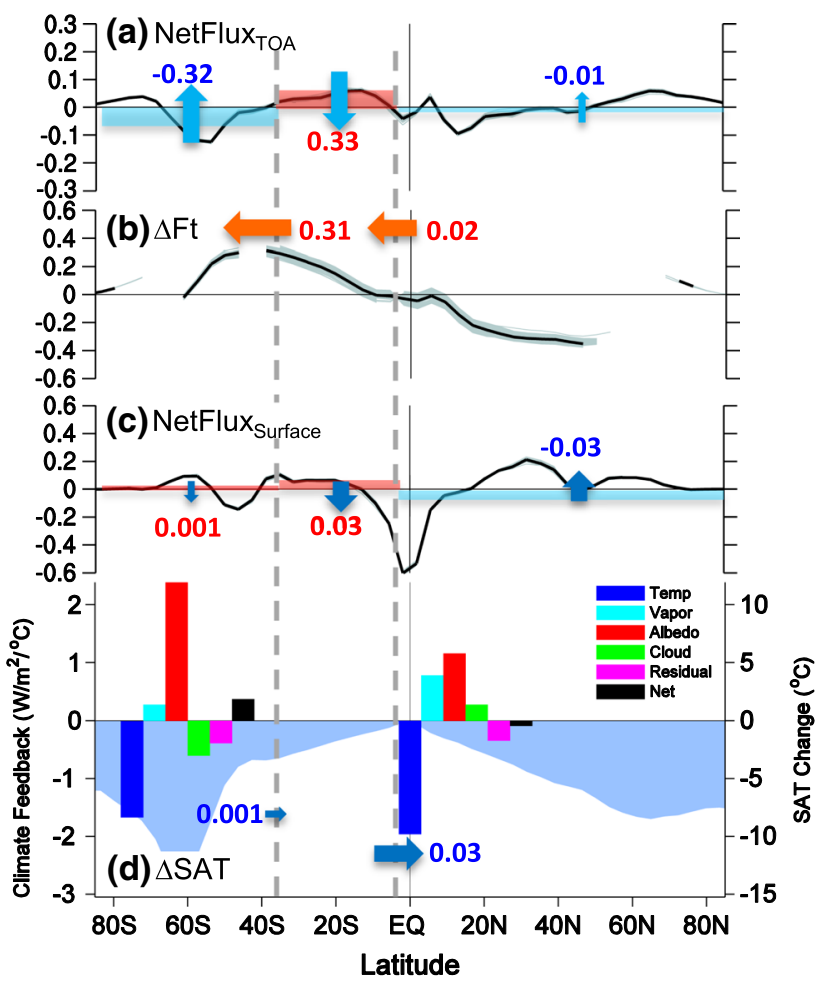

Fig. 10 Same as Fig. 8, except for 0.1G. The bars in d show the mean climate feedbacks averaged between $80^{\circ} \mathrm{S}$ and $35^{\circ} \mathrm{S}$ (left cluster) and between $5^{\circ} \mathrm{S}$ and $80^{\circ} \mathrm{N}$ (right cluster), respectively. The positive (negative) value represents positive (negative) climate feedback. The net positive climate feedback (left black bar) explains the overcompensation across $35^{\circ} \mathrm{S}$. The nearly zero net climate feedback (right black bar) explains the nearly perfect compensation across $5^{\circ} \mathrm{S}$ 
in the $0.1 \mathrm{~A}$ run. The good compensation within $10^{\circ} \mathrm{S}$ and $10^{\circ} \mathrm{N}$ (Fig. 10b) is due to the overall neutral feedback in the entire NH (black bar in the right cluster, Fig. 10d), which results from the cancelation of positive albedo (red bar) and water vapour (cyan bar) feedbacks (Fig. 10d) and negative LW feedback (blue bar, Fig. 10d). This can be also understood by the overall neural feedback in the entire SH. The difference of $0.1 \mathrm{G}$ from $0.1 \mathrm{~A}$ and $0.1 \mathrm{P}$ lies mainly in the Southern Ocean. There is a strong overcompensation in the extratropical SH (Fig. 10b), which is mainly due to the strong positive SW feedback in the extratropical SH (red bar in the left cluster, Fig. 10d).

The energy budget in the extratropical $\mathrm{SH}$ is depicted as follows. Here, we focus on the region south of $35^{\circ} \mathrm{S}$, where strong overcompensation occurs due to the positive sea icealbedo feedback. The strong ocean cooling in this region (Figs. 5a, 10d) is triggered by the shutdown of the Antarctic Circumpolar Current and then enhanced by the positive sea ice-albedo feedback (red bar in the left cluster, Fig. 10d). For the ocean, the energy loss across $35^{\circ} \mathrm{S}$ is negligible (Figs. 3b, 10d), due to the cancelation of anomalous winddriven northward OHT in the Indo-Pacific (Fig. 3d) and anomalous southward OHT in the Atlantic (Fig. 3c). The strong cooling in the surface ocean and atmosphere needs energy supply from the tropics through anomalous southward AHT, which can be accomplished by enhancing Hadley Cell and eddy activities. The anomalous AHT has to be strong enough to make up the heat loss at the TOA due to strong positive SW feedback (Fig. 10d). Therefore, the strong overcompensation occurs here (Fig. 10b).

\subsection{Energy balance between the two hemispheres}

The global-mean feedback is negative as expected (black bars in the middle cluster in Fig. 11), indicating that the climate is stable to wind perturbations. The negative LW feedback is mainly balanced by the positive albedo feedback. The water-vapor feedback is always positive and can be very important and comparable to the positive albedo feedback in certain situations (cyan and red bars in the middle cluster, Fig. 11b). The global-mean cloud feedback is less certain and can be either positive or negative, depending much on the perturbation situations. Based on the global-mean feedback, the overall $C_{R}$ can be estimated using Eq. (2) (Table 1). These theoretical values are consistent with the values obtained from Eq. (1) (also shown in Fig. 3b-d).

The energy balance between the two hemispheres is further examined. Note that in all the perturbation experiments, the SST in the NH is colder than that in the SH (Fig. 5) due to much reduced northward OHT across the equator (Fig. 3b-d, blue arrows in Fig. 11). Therefore, the SH atmosphere is warmer than that in the NH (Fig. 11), enhancing the northward AHT in order to maintain the energy

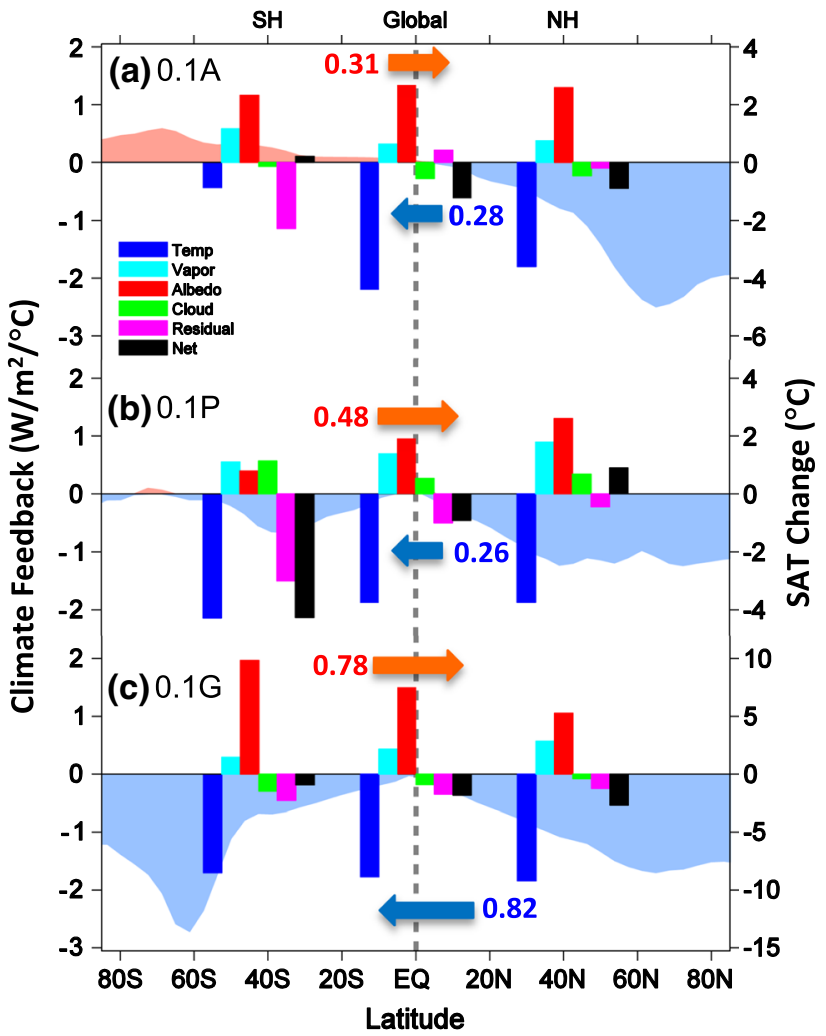

Fig. 11 Climate feedbacks $\left(\mathrm{W} / \mathrm{m}^{2} /{ }^{\circ} \mathrm{C}\right.$, color bars $)$ and zonallyaveraged $\triangle \mathrm{SAT}\left({ }^{\circ} \mathrm{C}\right.$, shade curve $)$ in a $0.1 \mathrm{~A}$, b $0.1 \mathrm{P}$ and $\mathbf{c} 0.1 \mathrm{G}$. The arrows and values show the direction and magnitude of $\Delta \mathrm{Fa}$ (red) and $\Delta \mathrm{Fo}$ (blue) across the equator, respectively. These values have an error bar of $\pm 0.02 \mathrm{PW}$. The climate feedbacks are averaged over the $\mathrm{SH}\left(90^{\circ} \mathrm{S}-0^{\circ}\right)$ (left cluster), the global $\left(90^{\circ} \mathrm{S}-90^{\circ} \mathrm{N}\right)($ central cluster) and the $\mathrm{NH}\left(0^{\circ}-90^{\circ} \mathrm{N}\right)$ (right cluster), respectively. Different color bars represent climate feedbacks by different processes shown in Eq. (4). The positive (negative) value represents positive (negative) climate feedback

balance between the two hemispheres (orange arrows). On the equator, the enhanced northward AHT does not always force the southward shift of the ITCZ, as suggested in Donohoe et al. (2013). The annual-mean ITCZ location in 0.1A (Fig. 5b) is hardly changed, and the AMOC shutdown does not force the ITCZ to shift southward. The AHT change at the equator is only $0.31 \mathrm{PW}$, which is not strong enough to move the ITCZ. Donohoe et al. (2013) have quantified that the location of ITCZ can be moved by about $3^{\circ}$ for $1 \mathrm{PW}$ AHT change at the equator. On the contrary, the STC shutdown in the Indo-Pacific does cause the southward shift of the ITCZ (Fig. 5a, c), because of significant change in AHT in the $0.1 \mathrm{G}$ and $0.1 \mathrm{P}$ runs. It appears that only the surface condition change in the tropical Indo-Pacific can result in changes in the ITCZ and Hadley Cell.

How the AHT responds to the OHT on the equator actually depends on the overall feedbacks in the two hemispheres based on the two-box approach illustrated in Fig. 7a. 
Table 1 Climate feedbacks related to different physical processes in three sensitivity experiments (units: $\mathrm{W} / \mathrm{m}^{2} /{ }^{\circ} \mathrm{C}$ ) and the Bjerknes compensation rate $\left(C_{R}\right)$

\begin{tabular}{lllllllll}
\hline Exps & Temp & Vapor & Albedo & Cloud & Residual & Net & $C_{\text {Rmodel }}$ & $C_{\text {Rtheory }}$ \\
\hline 0.1A & & & & & & & & \\
NH & -1.80 & 0.38 & 1.30 & -0.23 & -0.10 & -0.45 & -1.10 & -1.09 \\
SH & -0.44 & 0.58 & 1.16 & -0.07 & -1.14 & 0.10 & & \\
Global & -2.20 & 0.32 & 1.34 & -0.28 & 0.21 & -0.62 & -0.83 & -0.71 \\
0.1P & & & & & & & & \\
NH & -1.87 & 0.89 & 1.30 & 0.34 & -0.22 & 0.45 & -1.85 & -1.61 \\
SH & -2.14 & 0.55 & 0.39 & 0.57 & -1.50 & -2.13 & & \\
Global & -1.88 & 0.70 & 0.95 & 0.27 & -0.50 & -0.45 & -0.85 & -0.77 \\
$0.1 \mathrm{G}$ & & & & & & & & \\
NH & -1.84 & 0.57 & 1.05 & -0.08 & -0.25 & -0.54 & -0.95 & -0.91 \\
SH & -1.70 & 0.29 & 1.96 & -0.29 & -0.45 & -0.19 & & \\
Global & -1.77 & 0.43 & 1.51 & -0.18 & -0.35 & -0.36 & -0.87 & -0.81 \\
\hline
\end{tabular}

For $C_{R}$ on the equator, $C_{R \text { model }}=\frac{\Delta F_{a}}{\Delta F_{o}}$ and it is calculated based on the values on the equator in Fig. 11 . $C_{\text {Rtheory }}$ is obtained using Eq. (2), where $B_{1}$ and $B_{2}$ are the net mean climate feedbacks in the SH and $\mathrm{NH}$, respectively (Yang et al. 2016a). For global overall $C_{R}, C_{\text {Rmodel }}$ is obtained using Eq. (1) and $C_{\text {Rtheory }}=-\frac{1}{1-B / 2 \chi}$, where $B$ is the global overall negative feedback. Here, $\chi=1.5 \mathrm{~W} / \mathrm{m}^{2} /{ }^{\circ} \mathrm{C}$, based on previous studies (Marotzke and Stone 1995; Yang et al. 2015b). Note that $\chi$ can be within a range of 0.5$3.0 \mathrm{~W} / \mathrm{m}^{2} /{ }^{\circ} \mathrm{C}$ (North 1975 ), which would not change $C_{R}$ qualitatively. Negative (positive) value represents negative (positive) feedback. The feedback values have an error of about $\pm 0.01 \mathrm{~W} / \mathrm{m}^{2} /{ }^{\circ} \mathrm{C}$
There is weak (strong) overcompensation at the equator in the $0.1 \mathrm{~A}(0.1 \mathrm{P})$ (Fig. 11a, b), which results from a weak (strong) positive feedback over the $\mathrm{SH}(\mathrm{NH})$ in the $0.1 \mathrm{~A}$ (0.1P), due to the strong positive feedback related to albedo and water vapor. In the $0.1 \mathrm{G}$ (Fig. $11 \mathrm{c}$ ), there is a weak undercompensation at the equator, consistent with the overall negative feedbacks in both hemispheres, which is mainly resulted from the negative LW feedback. Detailed feedback values calculated from the "Radiative Kernel Technique" ("Appendix") and $C_{R}$ calculated directly from the data in Fig. 11 and theoretical formulae Eq. (2) are listed in Table 1. Although it is based on a highly-simplified box model by Yang et al. (2016a), the theoretical $C_{R}$ is highly consistent with that from the model output, implying that the intrinsic mechanism of BJC is captured by the theory, which in turn shed light on the BJC in a more complex system.

\section{Conclusion and discussion}

This work delved into the fundamental mechanism of BJC in a coupled climate model, focusing particularly on the roles of energy balance and local climate feedback. Although the BJC is well recognized in many coupled models, there is a lack of insight on the fundamental mechanism of BJC in a complex Earth system. Consistent with the theoretical studies of Liu et al. (2016) and Yang et al. (2016a), we confirm in this work that in a coupled system the energy constraint is a necessary condition for the occurrence of the BJC, and the local climate feedback determines how the BJC occurs. The different compensation scenarios in different regions are due to different local climate feedbacks. We show that no matter how different the climate responses are in these sensitivity experiments, the BJC occurs satisfying the same constraints: energy conservation and local feedbacks.

The understanding of the BJC based on energy constraint helps us to pursue the intrinsic connection between the radiative flux at the TOA and the ocean circulations. In particular, the ocean thermohaline circulation related to the deep-water formation in high latitudes may play a more substantial role than we thought in regulating the global energy balance on decadal and longer timescales, by modulating local climate feedbacks, such as those related to sea ice and to moisture and clouds in the atmosphere. This work provides a practical approach in studying the coupled dynamics of Earth system by investigating the coupling between the TOA radiative flux and the ocean circulations. Furthermore, this work shows the possibility in identifying the role of local climate feedback related to individual physical process in modulating the atmosphere and ocean circulations. In this study, we have not deliberated the connections of local feedback with specific physical processes.

The robustness of roles of energy conservation and local climate feedback in the BJC needs to be examined in other kinds of perturbation experiments (for example, freshwater forcing, greenhouse-gas forcing) and in other climate models. Previous studies (Vellinga and Wu 2008; Yang et al. 2013) showed that the BJC is valid in freshwater-forcing experiments. How the climate feedback plays a role in this situation has not been explored in details yet. In addition, our theoretical study (Yang et al. 2016a) showed that greenhouse-gas forcing in a simple coupled model can 
(a) $0.1 \mathrm{G}$

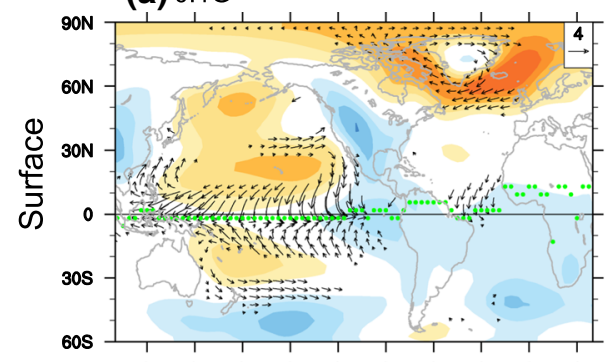

(b) $0.1 \mathrm{~A}$
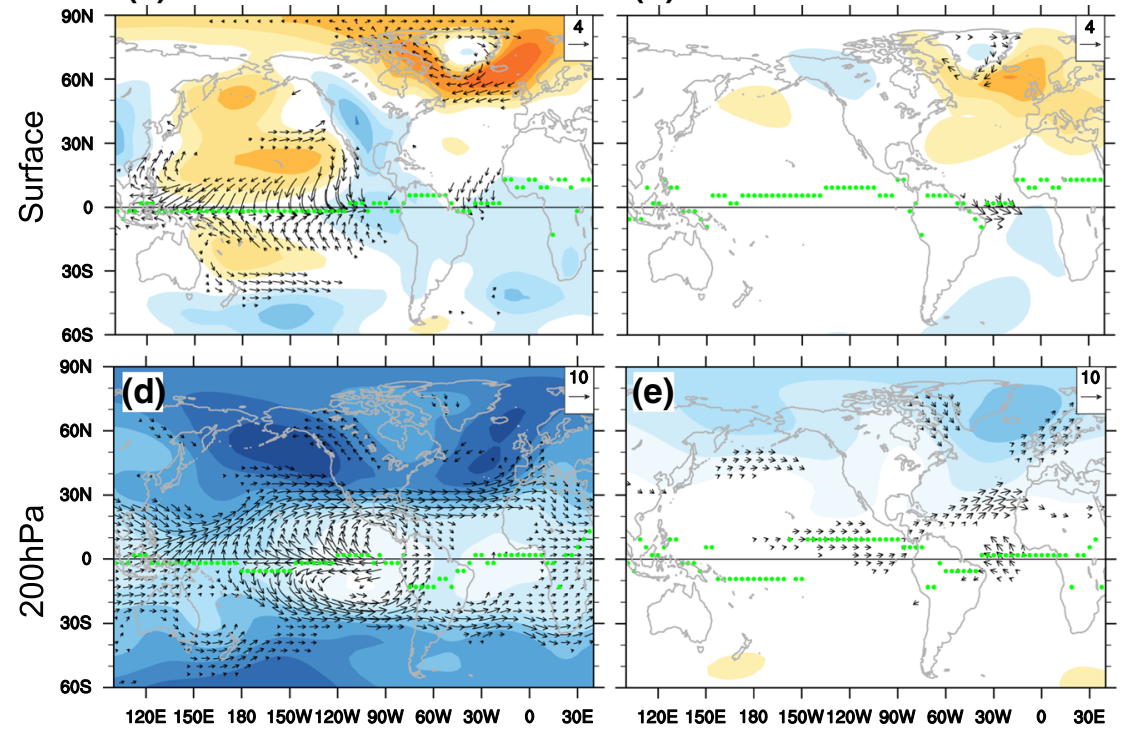

(c) $0.1 \mathrm{P}$
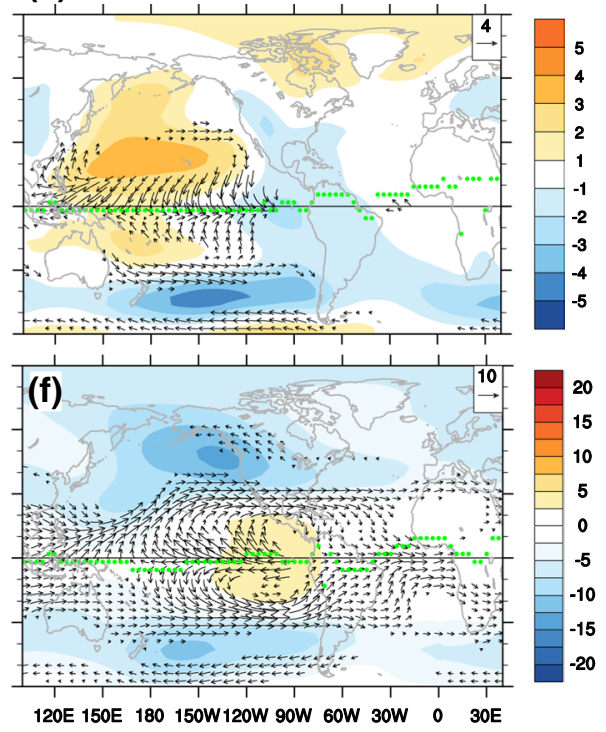

Fig. 12 Upper panels Changes in surface wind (vector, $\mathrm{m} / \mathrm{s}$ ) and surface pressure (contour, $\mathrm{hPa}$ ) in a $0.1 \mathrm{G}, \mathbf{b} 0.1 \mathrm{~A}$ and $\mathbf{c} 0.1 \mathrm{P}$. Lower panels same as the upper panels, except for $200-\mathrm{hPa}$ wind and geopoten-

result in failure of BJC because of the violation of global energy conservation. Whether the BJC remains valid in a coupled Earth system under greenhouse-gas forcing is a serious concern to us. This is because we believe the BJC plays a critical role in maintaining the stability of Earth climate system (Yang et al. 2015b), and the lack of BJC in a warming world may result in an acceleration of a runaway climate. Would the climate feedbacks in a warming climate be capable of adjusting enough to assure the occurrence of BJC? Besides these, in the framework of natural climate variability, the BJC is found valid on decadal and longer timescales (Shaffrey and Sutton 2006; Zhao et al. 2016). How the climate feedbacks and energy constraint play roles in the BJC variability needs to be explored. Our ongoing studies are seeking answers to these questions.

Finally, we would like to provide some supplementary discussions on the roles of the Pacific and Atlantic oceans in AHT changes. The Indo-Pacific is responsible for the AHT change in the tropics, while the Atlantic is more responsible for the AHT change in the extratropics. Moreover, the former is related to mean circulations, such as the Hadley Cell and the location of the ITCZ, while the latter is more related to eddy activities such as the storm track. Figure 12 shows changes in surface pressure and surface winds as well as in geopotential height and winds on the $200 \mathrm{hPa}$ isobaric level in three sensitivity experiments. We see clearly that only the SST change in the tropical Pacific can cause a significant shift of the ITCZ (Fig. 12a, c), and thus the tropical wind change in the whole atmospheric column (Fig. 12d, f). In contrast, the SST change in the Atlantic hardly affects the position of tial height (units: $10 \mathrm{~m}$ ). In a-f, the location of ITCZ is marked by the green dots. The wind changes of less than $1 \mathrm{~m} / \mathrm{s}$ in a-c and $2 \mathrm{~m} / \mathrm{s}$ in d-f are not plotted

the ITCZ; instead, it causes significant changes over Greenland (Fig. 12b, e). The change in eddy activities over Greenland is mainly contained in the lower troposphere, which is consistent with the strong baroclinic change in the wind and pressure fields (Fig. 12a, b, d, e). Following the conventional approach, the ITCZ position is defined as the latitude of the maximum convergence (divergence) of the surface wind (200 hPa wind) (Philander et al. 1996); the position is shown in Fig. 12. This helps us to understand the relative roles of tropical and extratropical atmosphere in the overall AHT.

Supplementary to Yang and Dai (2015), the sensitivity experiments in this work advance our fundamental understating on the relative roles of the Pacific and Atlantic in the global atmospheric heat budget. Moreover, we see clearly in the three experiments how the Earth's climate tries to maintain the energy balance between the two hemispheres. If the ocean in the $\mathrm{NH}$ is colder than that in the $\mathrm{SH}$ due to the reduced northward heat transport across the equator (Fig. 11), the atmosphere will respond to the ocean change with enhanced northward AHT across the equator, through either southward shift of the ITCZ in the tropics, or changes in local feedbacks, or increased eddy activities in high latitudes. Right on the equator, the BJC situation is determined by the difference of overall climate feedbacks in the two hemispheres.

Acknowledgments We are grateful to Prof. Z. Liu for valuable suggestions and discussions. This work is jointly supported by the NSF of China (No. 91337106, 41376007, 41176002, 40976007), the National Basic Research Program of China (No. 2012CB955200). All experiments are performed on the supercomputer at the LaCOAS, Peking University. 
Open Access This article is distributed under the terms of the Creative Commons Attribution 4.0 International License (http://creativecommons.org/licenses/by/4.0/), which permits unrestricted use, distribution, and reproduction in any medium, provided you give appropriate credit to the original author(s) and the source, provide a link to the Creative Commons license, and indicate if changes were made.

\section{Appendix: Identifying climate feedbacks}

Climate feedbacks in a coupled Earth System Model are complex. A so-called "Radiative Kernel Technique" can be used to quantify these climate feedback processes (Shell et al. 2008; Soden et al. 2008; Jonko et al. 2012; Zelinka and Hartmann 2012). In this approach, the net heat flux change at the TOA is qualitatively written as:

$\Delta R=\Delta \bar{T}_{s}\left(f_{T}+f_{q}+f_{\alpha}+f_{c}\right)+$ Residual,

where $\Delta R$ is the change of net radiation flux at the TOA; $\Delta \bar{T}_{S}$ is the change in global-mean surface temperature; $f_{T}, f_{q}$, $f_{\alpha}$, and $f_{c}$ are the radiative feedbacks resulting from changes in atmosphere temperature $T$, atmosphere water vapour $q$, planetary albedo $\alpha$, and total clouds $c$, respectively; Residual includes those that cannot be represented by the above processes plus calculation errors. These feedback parameters can be determined by the Kernel Technique as follows (Shell et al. 2008; Huang and Zhang, 2014):

$f_{T}=\frac{\partial R}{\partial T_{s}} \frac{d T_{s}}{d \bar{T}_{s}}+\frac{\partial R}{\partial T} \frac{d T}{d \bar{T}_{s}}=K_{T_{s}} \frac{d T_{s}}{d \bar{T}_{s}}+K_{T} \frac{d T}{d \bar{T}_{s}}$,
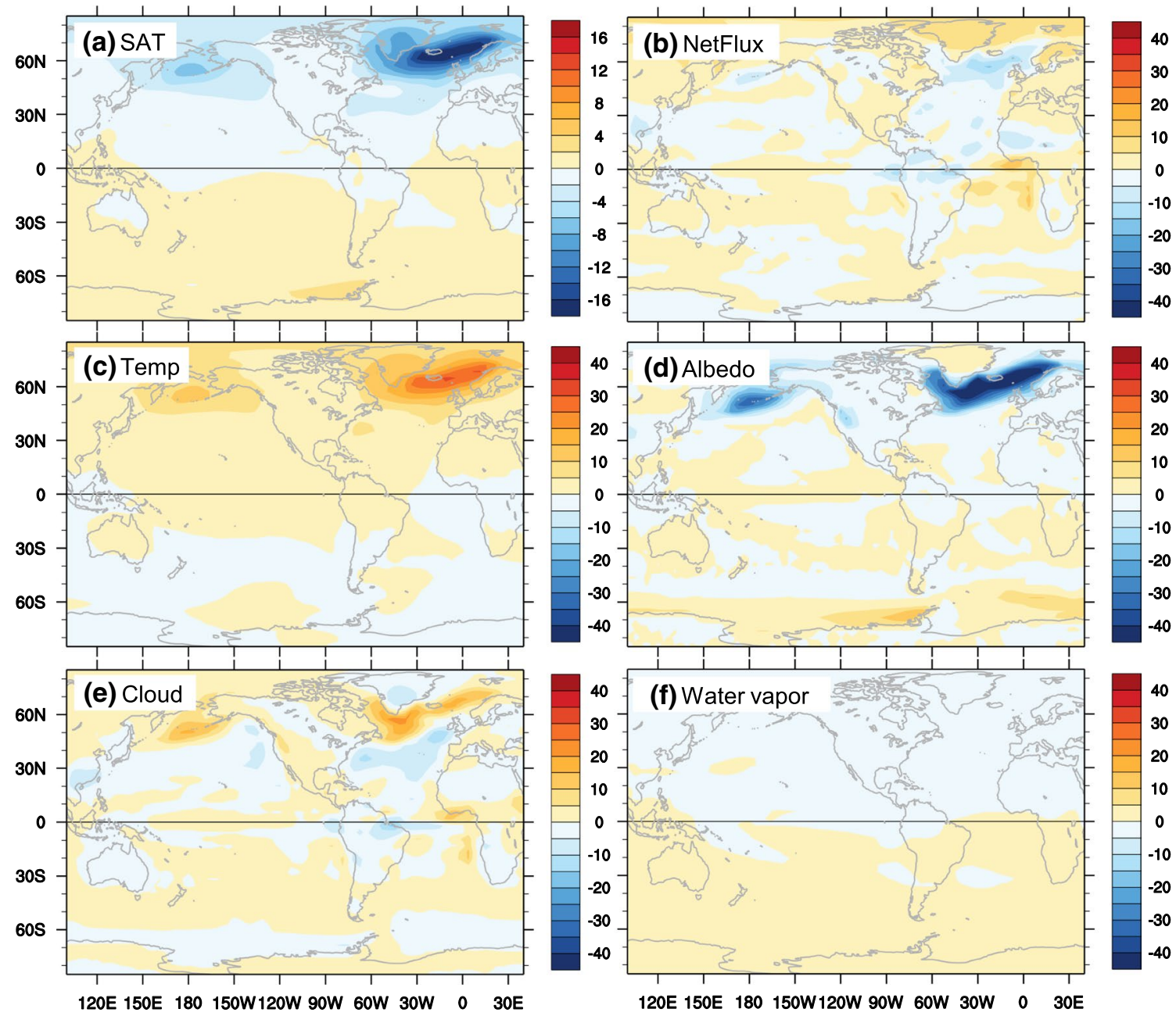

Fig. 13 Climate changes in 0.1A. a Surface air temperature change $\left({ }^{\circ} \mathrm{C}\right)$; b net radiation flux change at the TOA $\left(\mathrm{Wm}^{-2}\right)$, and the contributions from the change in $\mathbf{c}$ air temperature and surface temperature, d surface albedo, e total cloud, and $\mathbf{f}$ atmosphere water vapor. b-f
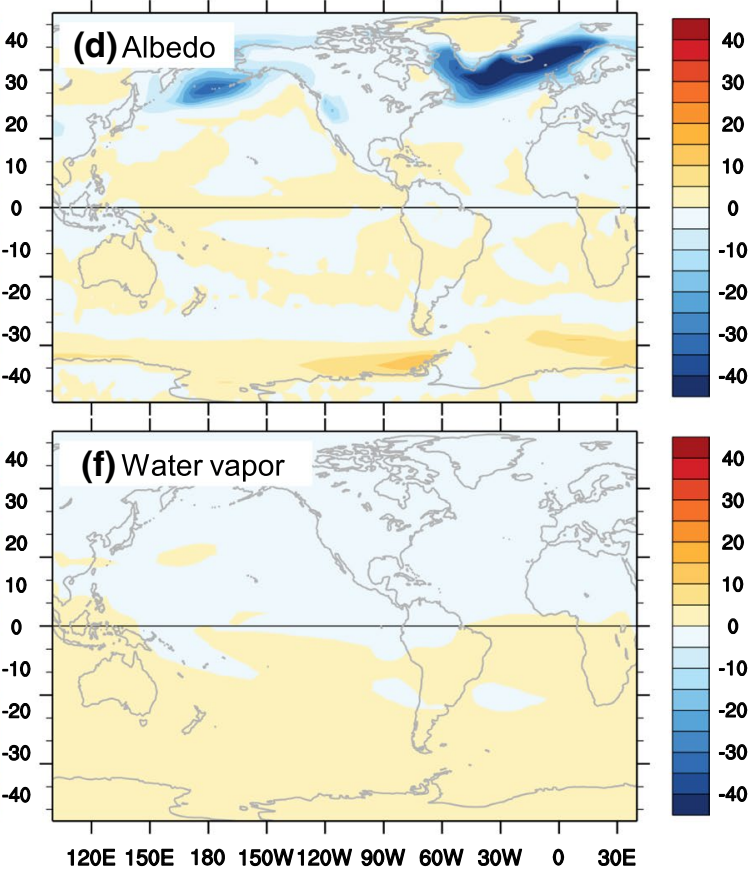

Negative value represents heat lose (outgoing) and the positive value represents heat gain (incoming) at the TOA. Same (opposite) signs between SAT and heat flux suggest a positive (negative) feedback 
$f_{q}=\frac{\partial R}{\partial \ln (q)} \frac{d \ln (q)}{d \bar{T}_{s}}=K_{q} \frac{d \ln (q)}{d \bar{T}_{s}}$,

$f_{\alpha}=\frac{\partial R}{\partial \alpha} \frac{d \alpha}{d \bar{T}_{s}}=K_{\alpha} \frac{d \alpha}{d \bar{T}_{s}}$

$f_{c}=\frac{\partial R}{\partial \mathrm{c}} \frac{d c}{d \bar{T}_{s}}=K_{c} \frac{d c}{d \bar{T}_{s}}$.

Here, $K_{x}$ represents the radiative kernel, which expresses the radiative flux change at the TOA due to perturbation in variable $x$. These kernel data $\left(K_{x}\right)$ are given by Shell et al. (2008) and Soden et al. (2008). We need to point out that $f_{T}$ contains feedbacks due to Planck thermal response and lapse rate, which include all direct effects by temperature changes (Zelinka and Hartmann 2012). Cloud feedback $\left(f_{c}\right)$ is determined by the difference of the total radiative flux from the model output and the clear-sky radiative flux calculated by the kernel technique. We have compared the latter with the model clear-sky net radiative flux and found them nearly identical in terms of both pattern and magnitude in all three perturbation experiments. This justifies our calculation of $f_{c}$. However, our kernel calculation did not separate the LW and SW cloud radiative forcing terms. The Residual term is generally small in our experiments. The climate feedback components are shown in Figs. 13, 14 and 15. Note that they are plotted as $\Delta \bar{T}_{s} * f_{x}$. This will not change the pattern and relative magnitude of $f_{x}$, since $\Delta \bar{T}_{s}$ is a constant for the perturbation experiments.

Here, we discuss briefly the errors in Eq. (4). The Residual term actually represents the discrepancy between the $\Delta R$ calculated from the four terms on the right hand side of Eq. (4) and the $\Delta R$ produced by the model. The Residual term should be small in principle, but it could be significant due to the following reasons (also see detailed discussions in Zelinka and Hartmann 2012). First, Eq. (4) assumes that the radiative impact of each component
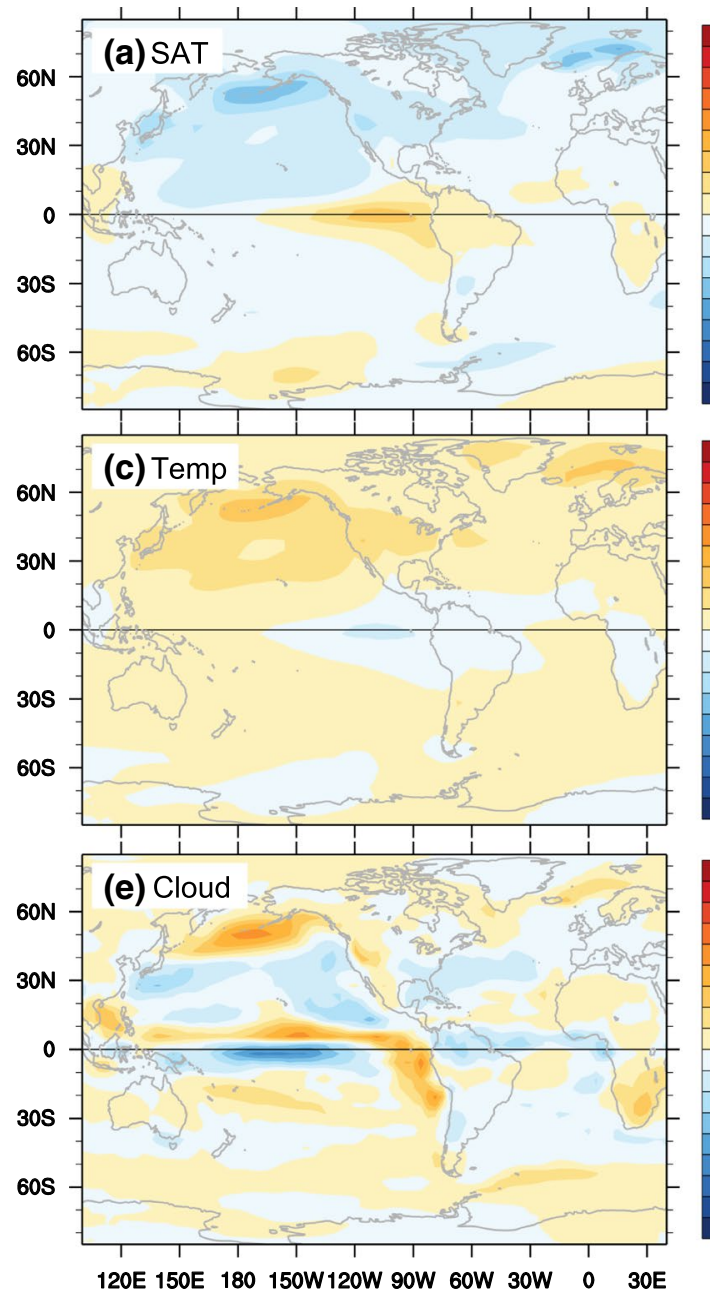
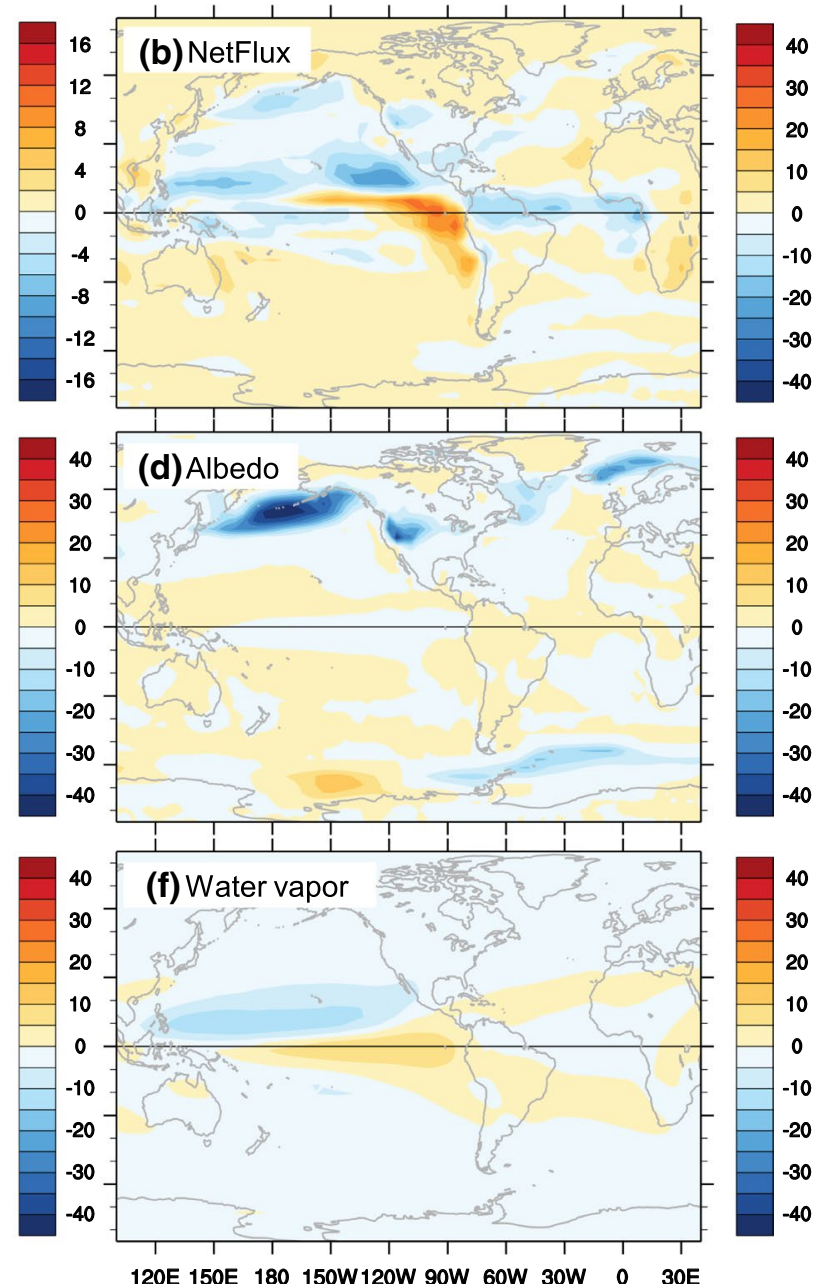

Fig. 14 Same as Fig. 13, except for climate changes in $0.1 \mathrm{P}$ 

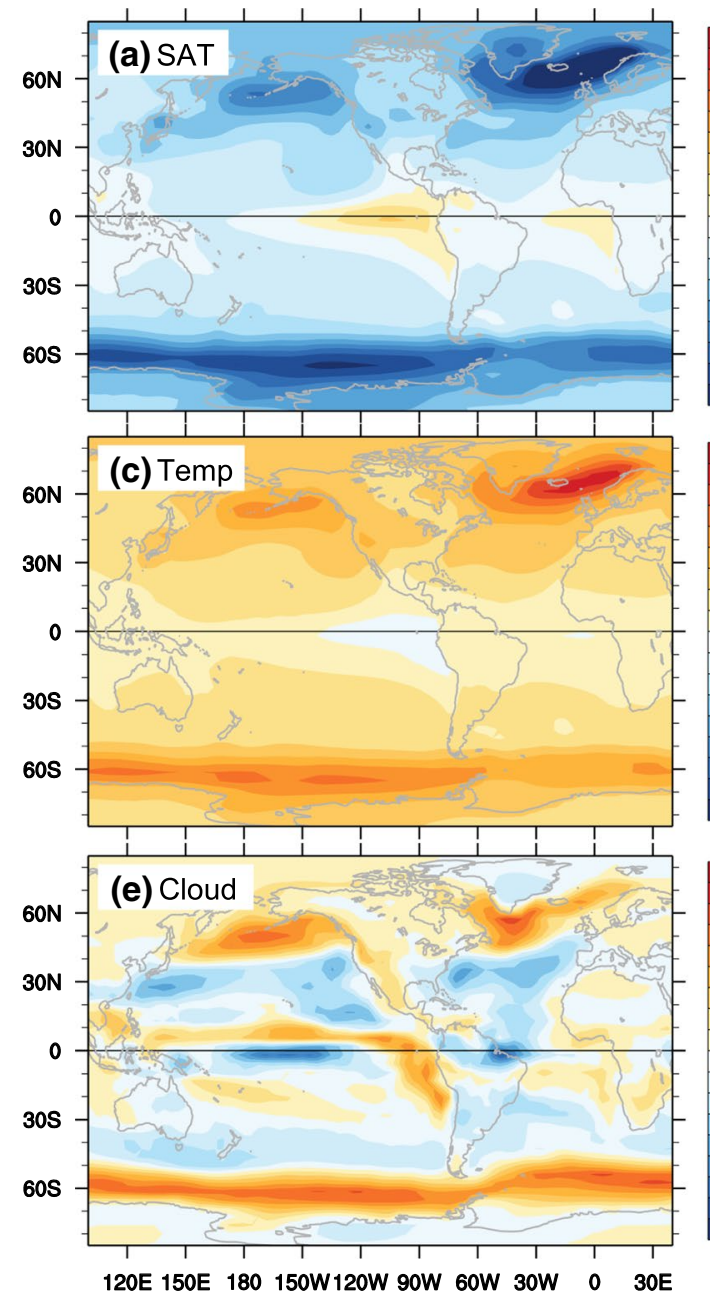

Fig. 15 Same as Fig. 13, except for climate changes in $0.1 \mathrm{G}$

change is independent of the others so that feedbacks can be added linearly to produce the TOA radiative flux anomaly, effectively ignoring interactions among feedbacks, which may be important. Second, one should not expect exact agreement between kernel-computed and modelgenerated TOA flux anomalies because the sensitivities of TOA radiation to small perturbations (i.e., the kernels) are generated using the GFDL model code and are then applied here to the NCAR CESM. Moreover, the mean state cloud fields in the GFDL model are different from those in the NCAR model, which introduce errors into cloud-masking adjustments. Third, the individual feedback terms defined in Eqs. (5)-(8) are assumed to represent radiative flux anomalies due to component changes that are linear functions of global-mean temperature changes. This assumption is apparently an oversimplification of the reality, particularly for the cloud feedback that can be closely related to atmosphere moisture and movement.
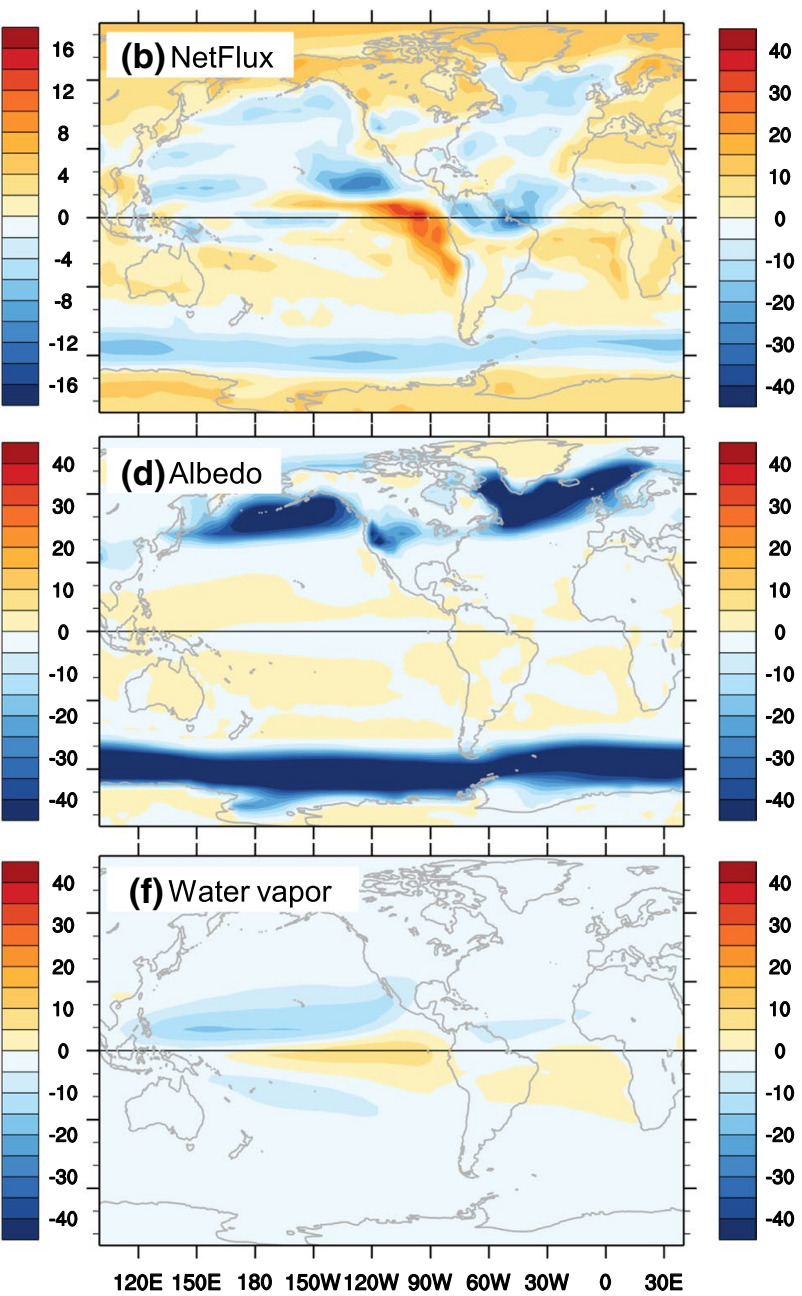

\section{References}

Bjerknes J (1964) Atlantic air-sea interaction. Adv Geophys 10:1-82 Cheng W, Bitz CM, Chiang JCH (2007) Adjustment of the global climate to an abrupt slowdown of the Atlantic meridional overturning circulation, Ocean Circulation: mechanisms and Impacts. Geophys. Monograph Series 173:295-313

Clement AC, Seager R (1999) Climate and the tropical oceans. J Clim 12:3383-3401

Danabasoglu G, Bates S, Briegleb BP, Jayne SR, Jochum M, Large WG, Peacock S, Yeager SG (2012) The CCSM4 Ocean Component. J Clim 25:1361-1389. doi:10.1175/ JCLI-D-11-00091.1

Donohoe A, Battisti DS (2012) What determines meridional heat transport in climate models? J Clim 25:3832-3850

Donohoe A, Marshall J, Ferreira D, Mcgee D (2013) The relationship between ITCZ location and cross-equatorial atmospheric heat transport: from the seasonal cycle to the Last Glacial Maximum. J Clim 26:3597-3618

Enderton D, Marshall J (2009) Explorations of atmosphere-ocean-ice climates on an aquaplanet and their meridional energy transports. J Atmos Sci 66:1593-1611 
Farneti R, Vallis GK (2013) Meridional Energy Transport in the Coupled Atmosphere-Ocean system: compensation and Partitioning. J Clim 26:7151-7166. doi:10.1175/JCLI-D-12-00133.1

Huang Y, Zhang M (2014) The implication of radiative forcing and feedback for meridional energy transport. Geophys Res Lett 41:1665-1672. doi:10.1002/2013GL059079

Hunke E, Lipscomb W (2008) CICE: The Los Alamos Sea Ice Model, documentation and software user's manual, version 4.0. Tech. Rep. LA-CC-06-012, Los Alamos National Laboratory

Jonko AK, Shell KM, Sanderson BM, Danabasoglu G (2012) Climate feedbacks in CCSM3 under changing $\mathrm{CO} 2$ forcing. Part I: adapting the linear radiative kernel technique to feedback calculations for a broad range of forcings. J Clim 25:5260-5272

Kang SM, Held IM, Frierson DMW, Zhao M (2008) The response of the ITCZ to extratropical thermal forcing: idealized slab-ocean experiments with a GCM. J Clim 21:3521-3532

Kang SM, Frierson DMW, Held IM (2009) The tropical response to extratropical thermal forcing in an idealized GCM: the importance of radiative feedbacks and convective parameterization. J Atmos Sci 66:2812-2827

Langen PL, Alexeev VA (2007) Polar amplification as a preferred response in an idealized aquaplanet GCM. Clim Dyn 29:305-317

Lawrence DM, Oleson KW, Flanner MG, Fletcher CG, Lawrence PJ, Levis S, Swenson SC, Bonan GB (2012) The CCSM4 land simulation, 1850-2005: assessment of surface climate and new capabilities. J Clim 25:2240-2260. doi:10.1175/JCLI-D-11-00103.1

Lindzen RS, Farrell B (1977) Some realistic modifications of simple climate models. J Atmos Sci 34:1487-1501

Liu Z, Yang H, He C, Zhao Y (2016) A theory for Bjerknes compensation: the role of climate feedback. J Clim 29:191-208. doi:10.1175/JCLI-D-15-0227.1

Marotzke J, Stone P (1995) Atmospheric transports, the thermohaline circulation, and flux adjustments in a simple coupled model. J Phys Oceanogr 25:1350-1364

Meehl GA, Washington WM, Arblaster JM, Hu A, Teng H, Kay JE, Gettelman A, Lawrence DM, Sanderson BM, Strand WG (2013) Climate change projections in CESM1 (CAM5) compared to CCSM4. J Clim. doi:10.1175/JCLI-D-12-00572.1

Neale RB, et al (2010) Description of the NCAR community atmosphere model (CAM5.0), Tech. Rep. NCAR/TN-486 + STR, National Center for Atmospheric Research, Boulder, CO, USA

Neale R, Richter J, Park S, Lauritzen P, Vavrus S, Rasch P, Zhang M (2013) The mean climate of the Community Atmosphere Model (CAM4) in forced SST and fully coupled experiments. J Clim 26:5150-5168. doi:10.1175/JCLI-D-12-00236.1

North GR (1975) Theory of energy-balance climate models. J Atmos Sci 32:2033-2043

North GR (1984) The small ice cap instability in diffusive climate models. J Atmos Sci 41:3390-3395

Park S, Bretherton CS, Rasch PJ (2014) Integrating cloud processes in the community atmosphere model, version 5. J Clim 27:68216856. doi:10.1175/JCLI-D-14-00087.1

Philander SGH, Gu D, Halpern D, Lambert G, Lau N-C, Li T, Pancanowiski RC (1996) Why the ITCZ is mostly north of the equator. J Clim 9:2958-2972

Rose BE, Ferreira D (2013) Ocean heat transport and water vapor greenhouse in a warm equable climate: a new look at the low gradient paradox. J Clim 26:2117-2136

Rose BE, Marshall J (2009) Ocean heat transport, sea ice, and multiple climate states: insights from energy balance models. J Atmos Sci 66:2828-2843
Seo J, Kang SM, Frierson DM (2014) Sensitivity of intertropical convergence zone movement to the latitudinal position of thermal forcing. J Clim 27:3035-3042

Shaffrey L, Sutton R (2006) Bjerknes compensation and the decadal variability of the energy transports in a coupled climate model. J Clim 19:1167-1181

Shell KM, Kiehl JT, Shields CA (2008) Using the radiative kernel technique to calculate climate feedbacks in NCAR's Community Atmospheric Model. J Clim 21:2269-2282

Smith RD, et al (2010) The Parallel Ocean Program (POP) reference manual. Tech. Rep. LAUR-10-01853, Los Alamos National Laboratory

Soden BJ, Held IM, Colman R, Shell KM, Kiehl JT, Shields CA (2008) Quantifying climate feedbacks using radiative kernels. J Clim 21:3504-3520

Stone PH (1978) Constraints on dynamical transports of energy on a spherical planet. Dyn Atmos Oceans 2:123-139

Swaluw EVD, Drijfhout SS, Hazeleger W (2007) Bjerknes compensation at high northern latitudes: the ocean forcing the atmosphere. J Clim 20:6023-6032

Trenberth KE, Caron JM (2001) Estimates of meridional atmosphere and ocean heat transports. J Clim 14:3433-3443

Vallis GK, Farneti R (2009) Meridional energy transport in the coupled atmosphere-ocean system: scaling and numerical experiments. Quart J Roy Meteor Soc 135:1643-1660

Vellinga M, Wu P (2008) Relations between northward ocean and atmosphere energy transports in a coupled climate model. J Clim 21:561-575

Wunsch C (2005) The total meridional heat flux and its oceanic and atmosphere partition. J Clim 18:4374-4380

Yang H, Dai H (2015) Effect of wind forcing on the meridional heat transport in a coupled model: equilibrium response. Clim Dyn 45:1451-1470. doi:10.1007/s00382-014-2393-0

Yang H, Wang Y, Liu Z (2013) A modeling study of the Bjerknes compensation in the meridional heat transport in a freshening ocean. Tellus. doi:10.3402/tellusa.v65i0.18480

Yang H, Li Q, Wang K, Sun Y, Sun D (2015a) Decomposing the meridional heat transport in the climate system. Clim Dyn 44:2751-2768. doi:10.1007/s00382-014-2380-5

Yang H, Zhao Y, Liu Z, Li Q, He F, Zhang Q (2015b) Heat transport compensation in atmosphere and ocean over the past 22,000 years. Nature Scientific Reports 5:16661. doi:10.1038/srep16661

Yang H, Zhao Y, Liu Z (2016a) Understanding Bjerknes compensation in atmosphere and ocean heat transports using a coupled box model. J Clim 29:2145-2160. doi:10.1175/JCLI-D-15-0281.1

Yang H, Wang K, Dai H, Wang Y, Li Q (2016b) Wind effect on the Atlantic meridional overturning circulation via sea ice and vertical diffusion. Clim Dyn 46(11):3387-3403. doi:10.1007/ s00382-015-2774-z

Zelinka MD, Hartmann DL (2012) Climate feedbacks and their implications for poleward energy flux changes in a warming climate. $\mathrm{J}$ Clim 25:608-624

Zhang R, Kang SM, Held IM (2010) Sensitivity of climate change induced by weakening of the Atlantic Meridional Overturning Circulation to cloud feedback. J Clim 23:378-389

Zhao Y, Yang H, Liu Z (2016) Assessing Bjerknes compensation for climate variability and its timescale dependence. J Clim 29(15):5501-5512 